\title{
Plankton energy flows using a global size-structured and trait-based model
}

\author{
Gabriela Negrete-García ${ }^{\mathrm{a}, \mathrm{e}}$, Jessica Y. Luo ${ }^{\mathrm{b}, \mathrm{c}, \mathrm{e}}$, Matthew C. Long ${ }^{\mathrm{b}}$, Keith \\ Lindsay $^{\mathrm{b}}$, Michael Levy ${ }^{\mathrm{b}}$, Andrew D. Barton ${ }^{\mathrm{a}, \mathrm{d}}$ \\ ${ }^{a}$ Scripps Institute of Oceanography, University of California San Diego, La Jolla, CA \\ ${ }^{b}$ Climate 83 Global Dynamics Laboratory, National Center for Atmospheric Research, \\ Boulder, $C O$ \\ ${ }^{c}$ Geophysical Fluid Dynamics Laboratory, National Oceanic and Atmospheric \\ Administration, Princeton NJ \\ ${ }^{d}$ Section of Ecology, Behavior and Evolution, University of California, San Diego, CA, \\ USA \\ ${ }^{e}$ These authors contributed equally to the manuscript
}

\begin{abstract}
Plankton community models are critical tools for understanding the processes that shape marine plankton communities, how plankton communities impact biogeochemical cycles, and the feedbacks between community structure and function. Here, using the flexible Marine Biogeochemistry Library (MARBL), we present the Size-based Plankton Ecological TRAits (MARBLSPECTRA) model, which is designed to represent a diverse plankton community while remaining computationally tractable. MARBL-SPECTRA is composed of nine phytoplankton and six zooplankton size classes represented using allometric scaling relationships for physiological traits and interactions within multiple functional types. MARBL-SPECTRA is embedded within the global ocean component of the Community Earth System Model (CESM) and simulates large-scale, emergent patterns in phytoplankton growth limitation, plankton phenology, plankton generation time, and trophic transfer efficiency. The model qualitatively reproduces observed global patterns of surface nutrients, chlorophyll biomass, net primary production, and the biogeographies of a range of plankton size classes. In addition, the model simulates how predator:prey dynamics and trophic efficiency vary across gradients
\end{abstract}

Email addresses: g1negret@ucsd.edu (Gabriela Negrete-García), jessica.luo@noaa.gov (Jessica Y. Luo) 
in total ecosystem productivity. Shorter food chains that export proportionally more carbon from the surface to the ocean interior occur in productive regions, whereas in oligotrophic regions, the food chains are relatively long and export less organic matter from the surface. The union of functional type modelling with size-resolved, trait-based modelling approaches allows MARBL-SPECTRA to capture both large-scale elemental cycles and the structure of planktonic food webs affecting trophic transfer efficiency.

Keywords: plankton communities, trait-based models, phytoplankton, zooplankton, Earth system modelling

\section{Introduction}

Phytoplankton account for roughly half of the annual net primary pro3 ductivity on Earth (Field et al., 1998), and marine net primary production is I a fundamental constraint on total ecosystem production in the ocean. Phytoplankton are an extremely diverse set of microorganisms, ranging broadly in cell volume, cell morphology, and biogeochemical functions. The structure of plankton communities is shaped by variable physical, chemical, and predatory environments (Margalef, 1978). Marine plankton communities play key roles in biogeochemical cycling, which includes the export of carbon to the deep ocean (Henson et al., 2012) and the transfer of energy and organic matter to higher trophic levels (Ryther, 1969). Plankton community composition is important in regulating the efficiency of nutrient utilization and the character and quantity of exported organic matter on a regional and seasonal basis (Tréguer et al., 2018; Stemmann and Boss, 2012). Mechanistic representations of the distribution of plankton diversity, biogeography, and phenology over the global ocean are essential to predict the function of oceanic ecosystems and global biogeochemical cycles.

Coupled physical-biogeochemical models have long been used to better understand the processes that shape phytoplankton communities in the ocean. Historically, many marine plankton community models were constructed from a common nutrient-phytoplankton-zooplankton-detritus (NPZD) structure (Evans and Parslow, 1985; Fasham et al., 1990; Franks, 2002). Although these models ignore substantial biological complexity, when coupled to ocean circulation models, they provided large-scale estimates of biologicallymediated carbon fluxes (Six and Maier-Reimer, 1996). Modern day 'intermediate complexity' marine ecosystem models (Stock et al., 2014a; Moore 
et al., 2004b, 2013b; Aumont et al., 2015; Yool et al., 2013) coupled into Earth system models have been successful at simulating large-scale biogeographical variation in the efficiency of the biological pump and climate effects. Some have exhibited predictive capabilities for fisheries within Large Marine Ecosystems (Park et al., 2019) essential to sustain marine resources subject to climate-driven fluctuations and change. These marine ecosystem models typically include a minimum number of plankton functional types adequate for simulating broad plankton biogeography and biogeochemical interactions such as variations in export efficiency. However, they lack sufficient ecological resolution in the form of size-based differentiation within each plankton functional type to simulate the great diversity and complex interactions within plankton communities that are important to represent changes in community structure under climate change.

Trait-based models are a promising approach for increasing model diversity and ecological realism (Ward et al., 2012; Bruggeman and Kooijman, 2007; Follows et al., 2007; Dutkiewicz et al., 2019). Instead of simulating a few species or generic types of plankton, trait-based models resolve a higher diversity of organisms with distinct physiological and interaction traits, as well as trade-offs between these traits (Litchman et al., 2007). Trait-based models have been used to study the mechanisms shaping plankton biogeography, size structure, and diversity (Barton et al., 2010; Ward et al., 2012; Banas, 2011; Acevedo-Trejos et al., 2015; Monteiro et al., 2011; Follows et al., 2007). However, due to their higher complexity and greater computational cost, trait-based models are more difficult to embed in general circulation models (GCM) and implement in climate-timescale simulations.

Here we describe a new size-structured modelling framework, called MARBLSPECTRA, that leverages advances in trait-based modelling while remaining computationally tractable within coupled climate simulations. Using the Marine Biogeochemistry Library (MARBL) (Long et al., 2021), a configurable ocean biogeochemical model that has been coupled to the Community Earth System Model (CESM), we implement the Size-based Plankton Ecological TRAits (SPECTRA) model, leveraging MARBL's capacity for flexible ecosystem configuration. SPECTRA builds on the MARBL-CESM version 2.1 default ecosystem by expanding the number of groups within each phytoplankton and zooplankton functional type, using allometric scaling relationships to reduce the number of free parameters. MARBL-SPECTRA harmonizes the strengths of plankton functional type model representations crucial for capturing large-scale biogeochemical cycles, with the strengths 
of trait-based models aimed at representing the richness of plankton food webs and associated trophodynamics, under the constraint that it must be lean enough to be run for century-scale simulations. MARBL-SPECTRA includes nine phytoplankton groups belonging to four different plankton functional types (picoplankton, mixed phytoplankton, diatoms, and diazotrophs). It also includes six zooplankton groups divided into two microzooplankton $(<200 \mu \mathrm{m}$ ESD) and four mesozooplankton size classes (between $0.2 \mathrm{~mm}$ and $20 \mathrm{~mm}$ ). MARBL-SPECTRA allows us to better and more explicitly simulate plankton diversity while remaining computationally tractable to not preclude climate-timescale integrations within a global model. The model simulates important marine ecosystem dynamics such as phenology, biogeography, and trophic dynamics, as well as the coupled cycles of carbon, nitrogen, phosphorous, iron, silicon, and oxygen.

Here, we describe the features and assumptions of MARBL-SPECTRA and use the model to explore large-scale, emergent patterns in phytoplankton growth limitation, plankton phenology, plankton generation time, and trophic dynamics. The model results were validated against a comprehensive suite of biogeochemical observations, as well as independent estimates of phytoplankton and zooplankton productivity to assess MARBL-SPECTRA's ability to capture global-scale patterns in the transfer of energy through the planktonic food web. The model qualitatively reproduces observed global patterns of surface nutrients and chlorophyll biomass and is consistent with empirical estimates of global primary production and phytoplankton size distributions. We use the expansion of plankton communities in MARBLSPECTRA to explore growth limitation patterns between functional groups and size classes of phytoplankton. It also provides a venue to understand phenology and the trophic position of the plankton community, showing clear differences across productive and unproductive regions of the ocean. Using this model, we investigate mechanisms driving global patterns as well as regional differences in seasonal succession, generation time, and trophic scaling. These processes influence the rate of primary production, export, and transfer efficiency to higher trophic levels which are important in regulating the strength of the biological pump. 


\section{Methods}

\subsection{Size-based Plankton Ecological TRAits (SPECTRA) Model}

The Size-based Plankton Ecological TRAits (SPECTRA) planktonic community model is implemented using the Marine Biogeochemistry Library (MARBL) (Long et al., 2021), which is the ocean biogeochemical component within the Community Earth System Model (CESM). MARBL is designed to allow for a flexible number of plankton functional types, and in its default configuration, invokes an updated version of the marine ecosystem of its predecessor, the Biogeochemistry Elemental Cycle (BEC) model (Moore et al., 2001, 2004b, 2013b). MARBL-SPECTRA is a new configuration of MARBL that resolves nine phytoplankton (Fig. 1) ranging in size from 0.47 $\mu \mathrm{m}$ to $300 \mu \mathrm{m}$ in equivalent spherical diameter (ESD; (Fig. 1)). The nine model phytoplankton include one picoplankton, one diazotroph, three sizes of diatoms, and four sizes of mixed phytoplankton. Size classes were chosen such that: 1) within each phytoplankton group, characteristic size (geometric mean of the size range) was evenly spaced on a $\log _{10}$ scale, and 2) size classes across functional types were overlapping but not identical. The picoplankton group is analogous to Prochlorococcus and Synechococcus with a characteristic size of $0.89 \mu \mathrm{m}$ ESD. Diazotrophs fix nitrogen and have a characteristic size of $6.2 \mu \mathrm{m}$ ESD. Diatoms, the silicifiers in the community, range in size between $20 \mu \mathrm{m}$ to $200 \mu \mathrm{m}$ ESD. The mixed phytoplankton size ranges from $1.7 \mu \mathrm{m}$ to $300 \mu \mathrm{m}$ ESD, and represent solitary protists not included in the other functional groups, such as picoeukaryotes and autotrophic dinoflagellates. Within the mixed phytoplankton group, implicit calcifiers (including coccolithophores) are represented by size classes between $3 \mu \mathrm{m}$ and $25 \mu \mathrm{m}$ to encompass the main species of coccolithophores (e.g., Emiliania huxleyi) (Aloisi, 2015). Phytoplankton ESD was converted to carbon biomass according to carbon:biovolume (C:BV) relationships, for picoplankton (Bertilsson et al., 2003), small nanoplankton (Reynolds, 2006), diatoms, and other nondiatom phytoplankton (Menden-Deuer and Lessard, 2000). The traits and parameters for each model phytoplankton are determined by their body size and functional group, which we describe in greater detail below. 


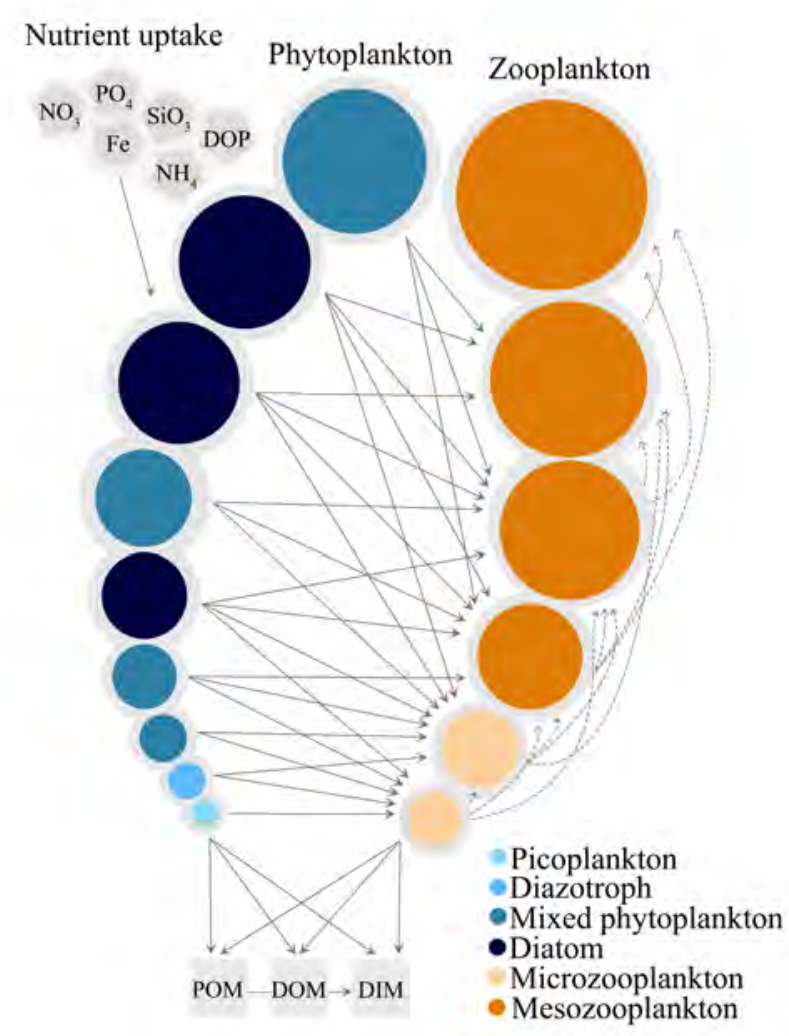

Figure 1: Schematic representation of MARBL-SPECTRA Model. The plankton community is composed of nine phytoplankton groups belonging to four different functional types; picoplankton (light blue), diazotrophs (sky blue), mixed phytoplankton (medium blue), and diatoms (dark blue), and six zooplankton groups composed of microzooplankton (light orange), and mesozooplankton (bright orange). Inorganic nutrients are taken up by phytoplankton ( $\mathrm{SiO}_{3}$ is only taken up by diatoms) who are grazed by zooplankton. Larger circles indicate larger organisms, but the circles are not to scale. Straight arrows indicate phytoplankton consumption by zooplankton, while dotted arrows indicate zooplankton consumption by zooplankton. Mortality and aggregation transfer living organic material into sinking particulate and dissolved organic detritus. The fluxes to particulate organic matter (POM), dissolved organic matter (DOM), and dissolved inorganic matter (DIM) pools are shown as arrows from phytoplankton and zooplankton groups. 
MARBL-SPECTRA includes six zooplankton ranging in size from $20 \mu \mathrm{m}$ to $20 \mathrm{~mm}$ ESD (Fig. 1), with each zooplankton consuming multiple phytoplankton and zooplankton prey types. The smallest two zooplankton $(<200$ $\mu \mathrm{m}$ ESD) are heterotrophic organisms commonly referred to as microzooplankton. The smallest microzooplankton consumes only small phytoplankton, whereas the larger microzooplankton consumes both, small phytoplankton groups and the smallest microzooplankton. Mesozooplankton (between $0.2 \mathrm{~mm}$ and $20 \mathrm{~mm}$ ) correspond to the largest four zooplankton size classes (zoo3-zoo6) and include a range of organisms such as copepods, krill, chaetognaths, and some gelatinous zooplankton. The first three mesozooplankton size classes are omnivorous, able to consume a range of phytoplankton and zooplankton prey, while the largest mesozooplankton is carnivorous, ranging from 6.3 to $20 \mathrm{~mm}$ in size. These feeding relationships between predators and prey are depicted by the feeding preference coefficient with an predatorto-prey optimal size ratio of 12.5:1 and maximum and minimum of 50:1 and 1:1, respectively 2.4 (Law et al., 2009; Fuchs and Franks, 2010; Taniguchi et al., 2014; Heneghan et al., 2020). Notably excluded from the mesozooplankton are gelatinous zooplankton like salps and pyrosomes with extremely wide predator-to-prey size ratios (e.g., between 10,000:1 and 50:1) (Conley et al., 2018). Zooplankton ESD was converted to carbon biomass using microzooplankton values from Menden-Deuer and Lessard (2000) and general non-gelatinous mesozooplankton values from Pitt et al. (2013).

MARBL-SPECTRA leverages MARBL's flexible ecosystem configuration, which represents phytoplankton types $P_{i}$ and grazers $Z_{j}$, where $P_{i}$ $\left(\mathrm{mmol} \mathrm{C} \mathrm{m}^{-3}\right)$ is the phytoplankton biomass of the of the $i^{\text {th }}$ phytoplankton type, and $Z_{j}\left(\mathrm{mmol} \mathrm{C} \mathrm{m}^{-3}\right)$ is the zooplankton biomass of the $j^{\text {th }}$ zooplankton type. The rate of change of biomass for the $i^{t h}$ phytoplankton is a balance of growth and losses to grazing (predation), mortality, and aggregation, in addition to physical transport processes not shown here. Key model symbols and units are summarized in Tables 1, 2, and 3. See Long et al. (2021) for a comprehensive presentation of the plankton community in CESM, version 2.

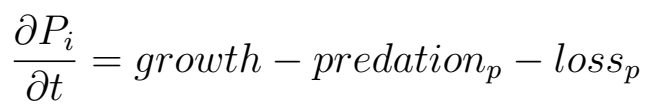

Phytoplankton growth (mmol $\left.\mathrm{C} \mathrm{m}^{-3} \mathrm{~d}^{-1}\right)$ is determined by a carbonspecific, light-saturated photosynthesis rate $P C_{i}^{m}\left(\mathrm{~d}^{-1}\right)$ for each phytoplankton group, modulated by a non-dimensional factor which reflects sensitivities to light $\left(\gamma_{i}^{I}\right)$ : 


$$
\text { growth }=P C_{i}^{m} \gamma_{i}^{I} P_{i}
$$

The light sensitivity of growth rate $\left(\gamma_{i}^{I}\right)$ is parameterized using a modified form of the Geider et al. $(1997,1998)$ dynamic growth model (Eq. 3), where $\alpha_{i}^{C h l}\left(\mathrm{mmol} \mathrm{C} \mathrm{m}{ }^{2}(\mathrm{mg} \mathrm{Chl} \mathrm{W} \mathrm{d})^{-1}\right)$ is the Chl-specific initial slope of the photosynthesis irradiance curve, $I\left(\mathrm{~W} \mathrm{~m}^{-2}\right)$ is the instantaneous irradiance, and $\theta_{i}^{C}$ is the $C h l: \mathrm{C}$ ratio $\left(\mathrm{mg} \mathrm{Chl} \mathrm{mmol} \mathrm{C}^{-1}\right)$, as follows:

$$
\gamma_{i}^{I}=1-e^{\frac{-\alpha_{i}^{C h l_{\theta} C_{I}}}{P C_{i}^{m i}}}
$$

MARBL also uses a multi-column subgrid scale treatment for light, following Long et al. (2015), which reduces biases when light fields are heterogeneous, such as high latitude spring bloom conditions. The above equation describes the biomass-specific rate of photosynthesis as a saturating function of irradiance. $P C_{i}^{m}$ is expressed as a function of the reference carbon-specific photosynthesis rate $\left(P C_{i}^{r e f}\right)\left(\mathrm{d}^{-1}\right)$ (the maximum achievable carbon-specific photosynthesis rate at the reference temperature) for each phytoplankton group, the temperature dependence function $\left(\gamma_{i}^{T}\right)$, and the nutrient limitation function $\left(\gamma_{i}^{N}\right)$ for each phytoplankton type. $\alpha_{i}^{C h l}, \theta_{i}^{C}$ and $P C_{i}^{\text {ref }}$ are set according to allometric relationships defined by Edwards et al. (2015a), Geider et al. (1997) and (Marañón et al., 2013) explained in more detail in Section 2.2.

$$
P C_{i}^{m}=P C_{i}^{r e f} \gamma_{i}^{T} \gamma_{i}^{N}
$$

Nutrient limitation of growth $\left(\gamma_{i}^{N}\right)$ is determined by the most limiting nutrient resource $\left(\mathrm{mmol} \mathrm{m}^{-3}\right)$ for that phytoplankton, computed using Liebig's Law of the Minimum:

$$
\gamma_{i}^{N}=\min \left(N_{N, i}^{l i m}, N_{P, i}^{l i m}, N_{F e, i}^{l i m}, N_{S i, i}^{l i m}\right)
$$

where the nutrients considered are nitrogen, iron, silicate, and phosphorous, yet not all nutrients are required for each phytoplankton group. Diatoms require nitrogen, phosphorous, silicate, and iron. Picoplankton, the mixed phytoplankton group and diazotrophs do not assimilate silicate, and diazotrophs are not limited by nitrogen due to their nitrogen fixing abilities. Simultaneous limitation by multiple nitrogen forms, i.e., nitrate $\left(\mathrm{NO}_{3}\right)$ and ammonium $\left(\mathrm{NH}_{4}\right)$, is represented following the substitutable model of O'Neill et al. (1989); See Long et al. (2021) for more details. A similar 
approach is used to compute limitation terms for phosphate $\left(\mathrm{PO}_{4}\right)$ and semiliable dissolved organic phosphate (DOP). The effect on growth rate of each of these nutrients for each phytoplankton is represented according to MichaelisMenten kinetics:

$$
N_{i}^{l i m}=\frac{N}{N+k_{i}}
$$

where, $k_{i}\left(\mathrm{mmol} \mathrm{N} \mathrm{m}^{-3}\right)$ represents the half-saturation nutrient concentration for each phytoplankton type $i$ set according to allometric relationships defined by Edwards et al. (2012) explained in more detail in Section 2.2.4.

In contrast to the default MARBL configuration, which uses the Eppley (Eppley, 1972) temperature scaling with the $Q_{10}$ factor, here, the temperature modulation of growth for each phytoplankton $\left(\gamma_{i}^{T}\right)$ is represented by the Arrhenius-Van't Hoff equation (Arrhenius, 1915). Kremer et al. (2017) found that the Arrhenius-Van't Hoff temperature scaling function more closely matched observations of how phytoplankton growth rates scale with temperature. Here, the temperature modulation of phytoplankton rates is expressed relative to the metabolic rate at a reference temperature.

$$
\gamma_{i}^{T}=e^{\left(\frac{-E a\left(T_{0}-T\right)}{k T_{0} T}\right)}
$$

where, $E a$ is the activation energy $(\mathrm{eV}), k$ is the Boltzmann's constant $\left(k=8.617 \times 10^{-5} \mathrm{eV} \mathrm{K}^{-1}\right), T$ is temperature $\left({ }^{\circ} \mathrm{K}\right)$, and $T_{0}$ represents the reference temperature in the model $\left(293.15^{\circ} \mathrm{K}\right)$. Ea for all phytoplankton is set to $0.32 \mathrm{eV}$ (Kremer et al., 2017), except for picoplankton, where $E a^{p p}$ is set to $0.42 \mathrm{eV}$, a value derived from an analysis of the Kremer et al. (2017) dataset. Multiple studies have shown that picoplankton have a higher temperature sensitivity compared to phytoplankton of larger sizes (Chen et al., 2014; Stawiarski et al., 2016; Anderson et al., 2021), and model experimentation showed that lower $E a$ is key for excluding picoplankton from polar regions, compared to lower temperature sensitivity of larger sizes.

Predation on phytoplankton ( predation $_{p}$; mmol $\mathrm{C} \mathrm{m}^{-3} \mathrm{~d}^{-1}$ ) is modeled using a Holling type II function, where predation pressure increases approximately linearly as prey increases, before saturating to a maximum rate at high prey concentrations:

$$
\text { predation }_{p}=\iota_{j}^{\max } \gamma_{j}^{T} \phi\left(\frac{P_{i}^{\prime}}{P_{i}^{\prime}+K^{P}}\right) Z_{j}
$$


Here, $\iota_{j}^{\max }\left(\mathrm{d}^{-1}\right)$ is the zooplankton maximum ingestion rate at a reference temperature, and scales with zooplankton size (Section 2.3.1). The temperature modulation of ingestion for each zooplankton $\left(\gamma_{j}^{T}\right)$ is similar to that of phytoplankton, but differs by having a greater zooplankton activation energy $\left(E a^{Z}\right)$ compared to autotrophs (Allen et al., 2005), as Rubisco carboxylation (rate limiting for photosynthesis) has a lower Ea than ATP synthesis (Allen et al., 2005; Ángel López-Urrutia et al., 2006). Thus, for zooplankton, $E a^{Z}$ are set to $0.55 \mathrm{eV}$, a value similar to Ángel López-Urrutia et al. (2006) observations. This is in contrast with the default version of MARBL, which uses the same temperature sensitivity for both phytoplankton and zooplankton processes. Among global ocean biogeochemical models, very few models use a higher temperature sensitivity for zooplankton vs. phytoplankton (e.g., PISCES Aumont et al., 2015); the majority of models use either the same scaling for all plankton (e.g., COBALT Stock et al., 2014b, 2020), or no temperature scaling of zooplankton rates (e.g., MEDUSA Yool et al., 2013). Using a higher temperature sensitivity in zooplankton vs. phytoplankton may have implications for phytoplankton-zooplankton coupling and trophic transfer, particularly under climate change, however, a systematic study has not yet been done.

$$
\gamma_{j}^{T}=e^{\left(\frac{-E a^{Z}\left(T_{0}-T\right)}{k T_{0} T}\right)}
$$

$K^{P}\left(\mathrm{mmol} \mathrm{C} \mathrm{m}^{-3}\right)$ is the half-saturation prey concentration which regulates ingestion efficiency at low prey concentrations, and is set as a constant value for all zooplankton (Section 2.3.1). $\phi$ (unitless) is the feeding preference coefficient, which describes the probability of a given predator ingesting prey of a particular size. The feeding preference coefficient will be discussed in greater detail in Section 2.4. $P_{i}^{\prime}$ is the phytoplankton concentration in excess of a temperature-and depth-dependent refuge, and is used to limit autotroph mortality at low biomass ( $\mathrm{mmol} \mathrm{C} \mathrm{m}^{-3}$ ) (Long et al., 2021).

Phytoplankton loss $\left(\operatorname{loss}_{p}\right.$; mmol $\left.\mathrm{C} \mathrm{m}^{-3} \mathrm{~d}^{-1}\right)$ is represented by a linear loss term $\left(m_{i}\right)\left(\mathrm{d}^{-1}\right)$ that includes non-predation mortality and a collection of density-independent processes such as dissolved organic matter (DOM) exudation, viral lysis, and cell death. $6 \%$ of phytoplankton loss is routed to dissolved organic carbon (DOC) and the remaining 94\% to the dissolved inorganic carbon (DIC). In MARBL-SPECTRA, instead of a single allometric scaling, linear mortality is set as a fraction of $P C_{i}^{r e f}$, with a factor of 0.02 for diatoms and 0.03 for all other phytoplankton. The lower linear mortality for 
diatoms provide a slight advantage over other phytoplankton, particularly in nutrient rich (upwelling and polar) regions:

$$
\operatorname{loss}_{p}=m_{i} P_{i}^{\prime} \gamma_{i}^{T}+A\left(P_{i}^{\prime}\right)
$$

$A\left(P_{i}^{\prime}\right)\left(\mathrm{mmol} \mathrm{C} \mathrm{m}^{-3} \mathrm{~d}^{-1}\right)$ represents loss of phytoplankton due to aggregation and unresolved predation, and this loss goes directly to particulate organic matter (POC).

$$
A\left(P_{i}^{\prime}\right)=a_{i}\left(P_{i}^{\prime}\right)^{2}
$$

$A\left(P_{i}^{\prime}\right)$ is parameterized by a "quadratic mortality" rate, $a_{i}\left(\mathrm{~d}^{-1} \mathrm{mmol}\right.$ $\left.\mathrm{C}^{-1} \mathrm{~m}^{3}\right)$ for all phytoplankton that falls between imposed minimum $\left(a_{i}^{\mathrm{min}}\right.$ $\left.\mathrm{P}_{i}^{\prime}\right)$ and maximum aggregation $\left(a_{i}^{\max } \mathrm{P}_{i}^{\prime}\right)$ rates.

As with phytoplankton, the time rate of change in zooplankton is a balance between growth and losses to predation and non-predation mortality:

$$
\frac{\partial Z_{j}}{\partial t}=\text { (ingestion }- \text { predation }_{z}-\text { loss }_{z}
$$

Zooplankton ingestion ( $\mathrm{mmol} \mathrm{C} \mathrm{m}^{-3} \mathrm{~d}^{-1}$ ) represents the predation gains by zooplankton from their prey, and $\zeta$ (unitless) represents the maximum gross growth efficiency coefficient (i.e., the maximum fraction of ingestion that goes to growth; Straile, 1997), and is set to be $30 \%$ for all zooplankton. Zooplankton $\left(Z_{j}\right)$ are able to feed on both phytoplankton $\left(P_{i}\right)$ and other zooplankton ( $Z_{k}$, this excludes the largest zooplankton), modulated by a feeding preference coefficient $(\phi)$. Ingestion is thus the total consumption for a zooplankton $\left(Z_{j}\right)$ :

$$
\text { ingestion }=\iota_{j}^{\text {max }} \gamma_{j}^{T} Z_{j} \phi\left(\left(\frac{P_{i}^{\prime}}{P_{i}^{\prime}+K^{P}}\right)+\left(\frac{Z_{k}^{\prime}}{Z_{k}^{\prime}+K^{P}}\right)\right)
$$

where $Z_{k}^{\prime}$ is the zooplankton concentration in excess of a temperatureand depth-dependent threshold, used to limit zooplankton mortality at low biomass $\left(\mathrm{mmol} \mathrm{C} \mathrm{m}{ }^{-3}\right) \cdot \gamma_{j}^{T}, \iota_{j}^{\max }, K^{P}$, and $\phi$ are described above.

Of the total zooplankton ingestion, $35 \%$ is egested, yielding an assimilation efficiency (AE) of $65 \%$, which is within the general range of $60-80 \%$ used for zooplankton (Carlotti et al., 2000). Partitioning of the egestion into the POC, DOC, and DIC fractions depends on zooplankton size, and is discussed further in Section 2.4.1. Active respiration is $35 \%$ of ingestion, with the remaining biomass-based (basal) respiration represented by the linear fraction 
Table 1: Size-independent biological parameters.

\begin{tabular}{|llll|}
\hline Parameter & Symbol & Value & Units \\
\hline \hline Phytoplankton activation energy & $E a$ & 0.32 & $\mathrm{eV}$ \\
Picoplankton activation energy & $E a^{p p}$ & 0.42 & $\mathrm{eV}$ \\
Zooplankton activation energy & $E a^{Z}$ & 0.55 & $\mathrm{eV}$ \\
Phytoplankton "quadratic mortality" & $a_{i}$ & 0.035 & $\mathrm{mmol} \mathrm{C}^{-1} \mathrm{~m}^{3} \mathrm{~d}^{-1}$ \\
rate & & 0.03 & $\mathrm{~d}^{-1}$ \\
Phytoplankton linear mortality scaling & $m_{i}$ & 0.02 & $\mathrm{~d}^{-1}$ \\
Diatom linear mortality scaling & $m_{\text {diat }}$ & 1.1 & $\mathrm{mmol} \mathrm{m}^{-3}$ \\
Grazing half-saturation coefficient & $K^{P}$ & & \\
\hline
\end{tabular}

of zooplankton loss $\left(\mathrm{mmol} \mathrm{C} \mathrm{m}^{-3} \mathrm{~d}^{-1}\right)$. Thus, zooplankton production becomes:

$$
\text { production }=\text { לingestion }-m_{j}\left(Z^{\prime}{ }_{j}\right) \gamma_{j}^{T}
$$

where $m_{j}$ is the basal respiration rate $\left(\mathrm{d}^{-1}\right)$, and is set following allometric relationships, as discussed in Section 2.4.1 (see also Table 3).

Except for the largest mesozooplankton, all other zooplankton are also predated upon by larger zooplankton. These predator-prey relationships are

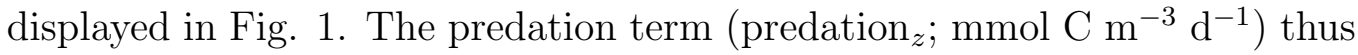
represents the predation losses from one zooplankton $\left(Z_{k}\right)$ to another $\left(Z_{j}\right)$ :

$$
\text { predation }_{z}=\iota_{j}^{\max } \gamma_{j}^{T} \phi\left(\frac{Z_{k}^{\prime}}{Z_{k}^{\prime}+K^{P}}\right) Z_{j}
$$

Zooplankton losses $\left(\operatorname{loss}_{z} ;\right.$ mmol $\left.\mathrm{C} \mathrm{m}^{-3} \mathrm{~d}^{-1}\right)$ consist of a linear loss term representing zooplankton mortality, as well as unresolved losses to higher tropic levels (Steele and Henderson, 1992), which are represented by a biomass- and temperature-dependent quadratic mortality term $\mathrm{a}_{j}\left(\mathrm{~m}^{3} \mathrm{mmol}\right.$ $\left.C^{-1} \mathrm{~d}^{-1}\right)$. The largest mesozooplankton size class has a higher quadratic loss mortality to compensate for higher trophic grazing not directly represented by grazing from the modeled ecosystem. Total non-predation losses include the linear (basal metabolic rate) and quadratic losses:

$$
l o s s_{z}=m_{j} \gamma_{j}^{T} Z_{j}^{\prime}+a_{j} \gamma_{j}^{T}\left(Z_{j}^{\prime}\right)^{2}
$$




\subsection{Allometric scaling of phytoplankton traits}

Many phytoplankton traits, such as metabolic rate and nutrient affinity, are related to cell size (Chisholm, 1992; Litchman et al., 2007; Edwards et al., 2012). There are also ecologically meaningful differences in key traits across phytoplankton functional groups. For example, large diatoms tend to grow more slowly than do smaller diatoms, but diatoms as a whole tend to grow more rapidly than other competing functional groups such as dinoflagellates (Litchman et al., 2007; Edwards et al., 2012). We use key trade-offs among functional traits to model community composition of marine phytoplankton along environmental gradients. For example, major functional traits in phytoplankton parameters such as nutrient-dependent growth and uptake have physiological trade-offs in the ability to acquire and utilize resources (Litchman et al., 2007). Incorporating these traits and trait trade-offs into a model allows it to represent the fundamental and realized ecological niche of a species and facilitates its representation across a range of environmental and biotic conditions (Ward et al., 2012; Follows et al., 2007). This approach has been used in a range of plankton community and biogeochemical models (e.g. Fuchs and Franks, 2010; Ward et al., 2012; Taniguchi et al., 2014; Dutkiewicz et al., 2015a; Heneghan et al., 2020). MARBL-SPECTRA adopts this approach, and ties organismal traits and interactions to body size and functional group by employing allometric rules to distinguish within plankton groups instead of individually tuning each plankton functional type. The use of these allometric relationships substantially reduces the number of free parameters.

The effect of size variation on phytoplankton traits is often idealized using a series of power-law scaling function with the typical form:

$$
t=\alpha V^{\beta}
$$

where $t$ is the physiological trait, $V$ is the cell volume across plankton in the model, $\alpha$ is a scaling constant, and $\beta$ is an exponent describing the size dependence. Below, we describe important allometric traits in the model, and discuss how our choices of $\alpha$ and $\beta$ across functional groups were informed by empirical studies across many phytoplankton sizes and functional groups (Litchman et al., 2007; Edwards et al., 2012; Marañón et al., 2013). Model traits are summarized in Fig. 2 and Tables 1 and 2. 
bioRxiv preprint doi: https://doi.org/10.1101/2022.02.01.478546; this version posted February 1, 2022. The copyright holder for this preprint (which was not certified by peer review) is the author/funder, who has granted bioRxiv a license to display the preprint in perpetuity. It is made is the author/funder, who has granted bioRxiv a license to display the preprint in perpetuity. It is made
available under adC-BY-NC-ND 4.0 International license.

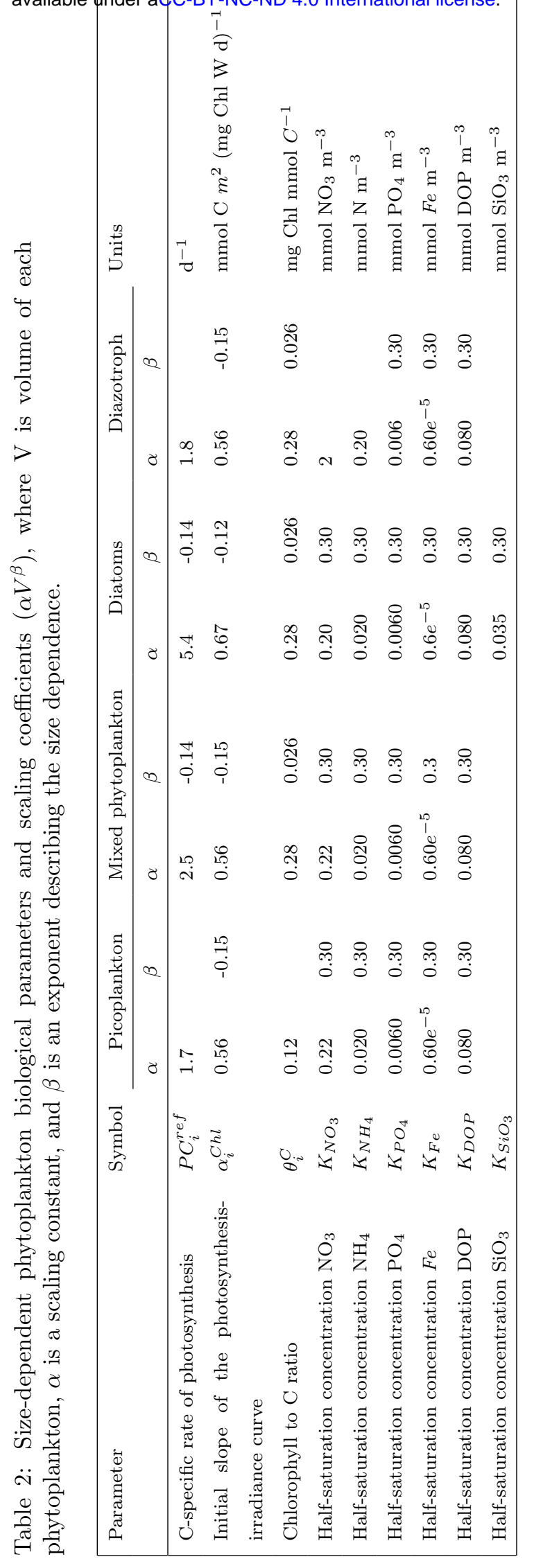



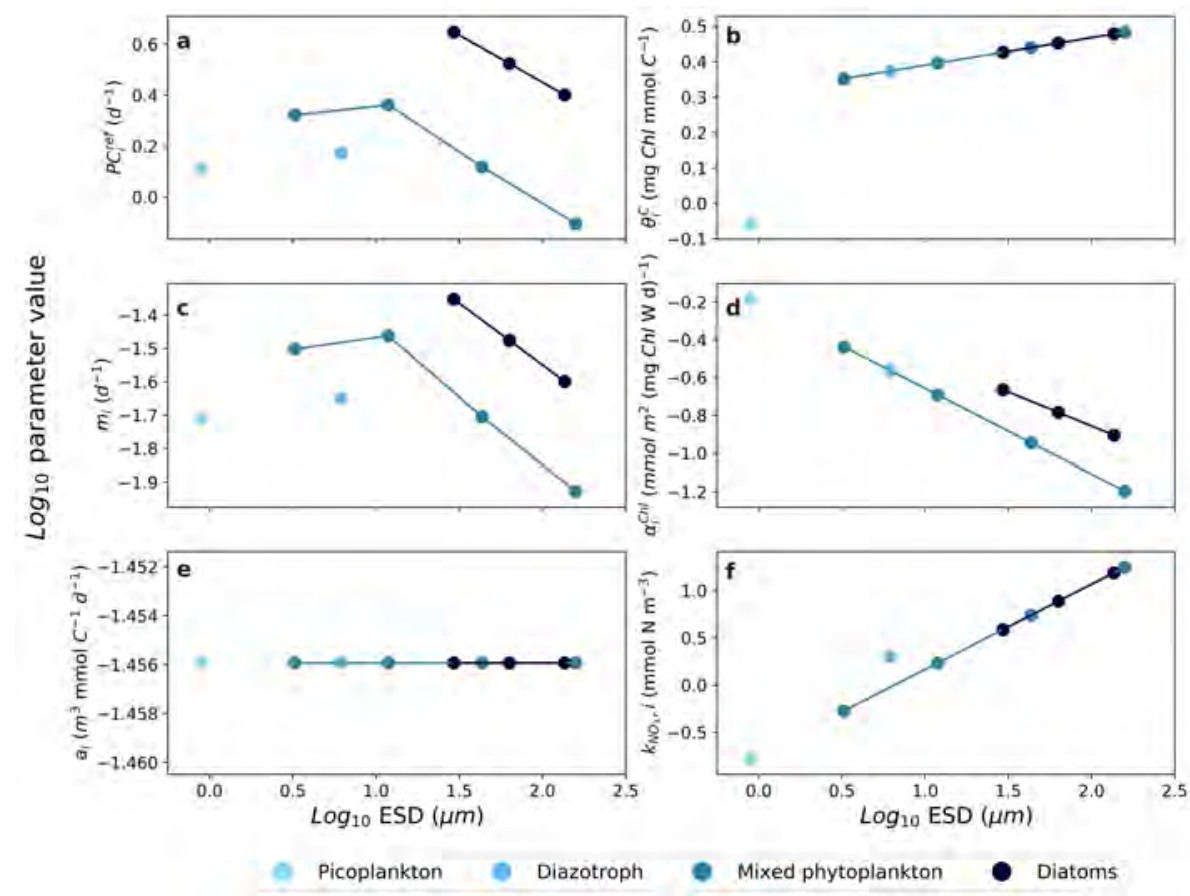

Figure 2: Model phytoplankton traits and parameters. Relationships for picoplankton (light blue), diazotrophs (sky blue), mixed phytoplankton (medium blue), and diatoms (dark blue), between equivalent spherical diameter (ESD) and (a) daily C-specific rate of photosynthesis $\left(P C_{i}^{r e f}\right)$ at a reference temperature $\left(20^{\circ} C\right)$, (b) Linear mortality $\left(\mathrm{m}_{i}\right),(\mathrm{c})$ aggregation loss $\left(\left(a_{i}\right)\right.$ representing aggregation and unresolved predation, $(\mathrm{d})$ maximum value of the Chl to phytoplankton carbon ratio $\left(\theta_{i}^{C}\right)$, (e) initial slope of photosynthesisirradiance curve $\left(\alpha_{i}^{C h l}\right)$, and half saturation nitrate concentration $\left(k_{\mathrm{NO}_{3}}\right)$.

\subsubsection{Phytoplankton growth and photosynthesis}

Within phytoplankton functional types and for cells larger than approximately $5 \mu \mathrm{m}$ ESD, phytoplankton $P C_{i}^{\text {ref }}$ rates generally decrease with increasing cell size (Marañón et al., 2013; Edwards et al., 2012; Tang, 1995). For phytoplankton smaller than $5 \mu \mathrm{m}$ ESD, larger cells grow faster than do smaller ones, such that the overall relationship between $P C_{i}^{\text {ref }}$ and cell size is unimodal, with the fastest growth rates achieved for cells around $5 \mu \mathrm{m}$ ESD (Marañón et al., 2013; Edwards et al., 2012; López-Sandoval et al., 2014). In addition, different functional groups tend to deviate from this overall pattern. Diatoms, for example, tend to grow faster than other groups (Edwards et al., 2012).

Consistent with this overall paradigm, $P C_{i}^{r e f}$ rates in MARBL-SPECTRA 
scale with cell volume and functional group with a scaling slope of -0.14 (Marañón et al., 2013) within functional types (Fig. 2a). Diatoms have higher $P C_{i}^{\text {ref }}$ rates than other groups, but within diatoms, $P C_{i}^{\text {ref }}$ decreases with body size ranging from $4.4 d^{-1}$ for the smallest diatoms, and $2.5 d^{-1}$ for the largest diatom, consistent with observations from Marañón et al. (2013) and López-Sandoval et al. (2014). The high $P C_{i}^{r e f}$ rates of diatoms facilitate their high biomass in nutrient-rich habitats and during bloom conditions (Margalef, 1978). Picoplankton have a low $P C_{i}^{\text {ref }}$ rate of $1.3 d^{-1}$ compared to quickly growing but somewhat larger cells. We have found that incorporating lower $P C_{i}^{r e f}$ rates for picoplankton and mixed phytoplankton smaller than $5 \mu \mathrm{m}$ ESD was essential for controlling small phytoplankton growth. Otherwise, the picoplankton and smallest mixed phytoplankton dominate, particularly in the higher latitude seasonal seas. $P C_{i}^{r e f}$ rates for the second smallest mixed phytoplankton through the largest mixed phytoplankton ranged between $2.3 d^{-1}$ and $0.8 d^{-1}$. Diazotrophs have $P C_{i}^{r e f}$ rates of $1.5 d^{-1}$, roughly half compared with other phytoplankton of their size, due to the high energetic demands of nitrogen fixation, which reduces growth rates (Margalef, 1978; Fu et al., 2005; Falcón et al., 2005; Breitbarth et al., 2008).

\subsubsection{Chlorophyll-carbon ratios}

The chlorophyll to carbon ratio $\left(\theta_{i}^{C}\right)$ reflects photoacclimation and nutrient stress and has been shown to track phytoplankton physiology both in the laboratory and in the field (Behrenfeld et al., 2005; Behrenfeld and Boss, 2003). Under the dynamic growth parameterization (Geider et al., 1997), the carbon-specific photosynthesis rate is a function of irradiance as well as $\theta_{i}^{C}$. Chl synthesis is regulated by the balance between light absorption and photosynthetic carbon fixation (Geider et al., 1998). Depending on this ratio, a fraction of newly assimilated nitrogen is diverted to the synthesis of Chl. $\theta_{i}^{C}$ values vary greatly among species and are affected nonlinearly by ambient nutrients, light, and temperature (Geider et al., 1997; Behrenfeld et al., 2002). $\theta_{i}^{C}$ is maximal at high temperatures and low irradiances under nutrient-replete conditions and declines at high irradiances, especially at low temperature and under nutrient limiting conditions (Geider et al., 1997). The maximum chlorophyll to carbon ratio $\left(\theta_{i}^{C}\right)$ is used as an input parameter in the model but is weakly constrained by empirical studies, with generally higher $\theta_{i}^{C}$ values for large diatoms and lower values for picoplankton such as Prochlorococcus (Geider et al., 1997; Sathyendranath et al., 2009). We therefore used a single allometric scaling relationship for most of the phyto- 
plankton, where $\theta_{i}^{C}$ ranges from $0.025-0.035\left[\mathrm{mg} \mathrm{Chl} \mathrm{mg} C^{-1}\right]$, except for picoplankton which have a $\theta_{i}^{C}$ of $0.01\left[\mathrm{mg} \mathrm{Chl} \mathrm{mg} C^{-1}\right]$ (Fig. 2b), to match with observed values (Hartmann et al., 2014; Li et al., 2010; Geider et al., 1998, 1986).

\subsubsection{Initial slope of the photosynthesis-irradiance curve}

Phytoplankton growth rates generally increase under increasing light up to an irradiance optima, at which point growth rates peak before declining due to photoinhibition at higher irradiance levels (Falkowski et al., 1985). These patterns can be illustrated by the photosynthesis-irradiance (P-I) curve, described by the initial slope of the P-I curve $\left(\alpha_{i}^{C h l}\right)$ and the biomass-specific rate of photosynthesis $\left(P C_{i}^{m}\right)$ under optimal irradiance (Eq. 3). Variations in $\alpha_{i}^{C h l}$ across phytoplankton can be explained in part by consistent differences between major taxonomic groups (Richardson et al., 1983; Cullen and MacIntyre, 1998; MacIntyre, 1998; Boyd et al., 2010) as well as cells of differing size (Geider et al., 1986; Finkel, 2001). Where, a decrease in $\alpha_{i}^{C h l}$ with cell size represents the ability of smaller cells to outperform larger cells under low-light conditions (Edwards et al., 2015a). This is consistent with self-shading of intercellular photosynthetic pigments, also referred to as the "Package effect" (Kirk, 1976), where as cell size increases, the same concentration of pigment, cellular volume, or unit of biomass will adsorb less light due to self-shading of pigment molecules (Kirk, 1994).

Discrepancies across functional types exist, with higher $\alpha_{i}^{C h l}$ in diatoms compared to other phytoplankton of similar sizes, due to the ability of diatoms to perform relatively well under both limiting light and excessive light (Richardson et al., 1983), or fluctuating light (Litchman, 1998) environments. Based upon the dataset of Edwards et al. (2015b), we set $\alpha$, and $\beta$ to be 0.67 mmol $\mathrm{C} \mathrm{m}^{2}$ (mg Chl W d) $)^{-1}$ and -0.12 for diatoms (Table $4 \&$ Fig. $2 \mathrm{~d}$ ). For other groups, we used $0.56 \mathrm{mmol} \mathrm{C} \mathrm{m}^{2}(\mathrm{mg} \mathrm{Chl} \mathrm{W} \mathrm{d})^{-1}$ and -0.15 respectively.

\subsubsection{Nutrient acquisition}

Phytoplankton growth in MARBL is a multiplicative factor of temperature, light, and nutrient limitation, with the nutrient limitation set by whatever nutrient concentration is lowest relative to the half-saturation constants for nutrient uptake (Moore et al., 2004b; Long et al., 2021). Experimental data and theoretical evidence demonstrates that smaller cells have higher rates of nutrient uptake per unit biomass and lower half-saturation constants 
(Eppley et al., 1969; Aksnes and Egge, 1991) compared to larger cells. The observed $\beta$ between $k$ and cell volume falls between 0.24 and 0.45 for $\mathrm{NO}_{3}$, and 0.29 to 0.56 for $\mathrm{PO}_{4}$ (Edwards et al., 2012). Since our model includes multiple limiting nutrients, we used a single size-scaling exponent of 0.3 for all nutrients. This means that within groups, picoplankton have more efficient nutrient uptake (smallest $k_{N}$ ) compared to the large diatoms and large mixed phytoplankton. Diazotrophs (e.g. Trichodesmium spp.) are the only exception from this allometric scaling, since they are less efficient at inorganic nutrient uptake (McCarthy and Carpenter, 1979) and they often occur as large colonies, where their surface to volume considerations imply higher half-saturation constants relative to the small phytoplankton and diatom groups (Letelier and Karl, 1998). However, higher half saturation constants for diazotrophs were only set for nitrogen and iron. See table 2 for all nutrient half-saturation constants and scaling coefficients.

MARBL-SPECTRA uses a fixed C:N:P stoichiometric ratio of nutrient uptake of 117:16:1 for all phytoplankton, which is a modified ratio following Anderson and Sarmiento (1994). While a dynamic model of C:P stoichiometry is provided within MARBL (Galbraith and Martiny, 2015; Long et al., 2021), enabling it with MARBL-SPECTRA would have added 15 additional tracers to the model, making computation extremely expensive. Additionally, we opted against using a size-dependent C:P stoichiometry (e.g., Finkel et al., 2010) to avoid undue complexity, as we found from initial tests that adding allometric C:P stoichiometry did not significantly impact plankton community composition in the present day. However, for future development of MARBL-SPECTRA, particularly for climate change experiments, size-dependent C:P stoichiometry can be explored.

Photoadaptation is calculated as a variable phytoplankton ratio of chlorophyll to nitrogen based on Geider et al. (1998). The model allows for variable $\mathrm{Fe} / \mathrm{C}$ and $\mathrm{Si} / \mathrm{C}$ ratios with an optimum and minimum value prescribed. As ambient $\mathrm{Fe}$ (or Si for diatoms) concentrations decline the phytoplankton lower their cellular quotas. Phytoplankton N/P ratios are fixed at the Redfield value of 16 , but the diazotroph group has a higher $\mathrm{N} / \mathrm{P}$ atomic ratio of 50 (see a detailed description of the model in Moore et al. (2001, 2004a)). Thus, community $\mathrm{N} / \mathrm{P}$ uptake varies with the phytoplankton community composition. 


\subsection{Zooplankton allometric scaling terms}

\subsubsection{Zooplankton Ingestion}

The vital rates of organisms depend on their size: ingestion, metabolism, and growth rates all increase with body size to a power of approximately 0.75 , typically such that the mass-specific rates decline with body mass to a power of near -0.25 (Peters and Wassenberg, 1983; Kiørboe and Hirst, 2014; Hansen et al., 1997). In MARBL-SPECTRA, zooplankton are defined as heterotrophs that can consume phytoplankton, other zooplankton, or a combination of both. Zooplankton ingestion rates are calculated as a function of prey carbon concentrations using the Hollings type II (Michaelis-Menten) function. There are two free parameters, maximum ingestion rate $\left(\iota_{j}^{\max }\right)$ and the half-saturation constant for grazing $\left(K^{P}\right)$.

Size-based variations in maximum specific ingestion rates were calculated as an allometric function of the predator biomass, with biomass-specific rates decreasing as biomass increases (Hansen et al., 1997). $\iota_{j}^{\max }$ are also modified by the feeding preference coefficient, which is a function of the ratio between the predator size and the prey size. $K^{P}$ are highly variable and typically hard to constrain. Across all the zooplankton classes, $K^{P}$ has been found to be independent of body size (Hansen et al., 1997). Therefore, the effective $K^{P}$ is set to $1.1\left(\mathrm{mmol} \mathrm{C} \mathrm{m}^{-3}\right)$ across zooplankton types (table 3 ).

\subsection{Predator-prey relationships}

In addition to physiological rates, predation in marine ecosystems is sizespecific, with larger prey eating a characteristic size range of smaller prey (Sheldon et al., 1977; Hansen et al., 1994; Cohen et al., 1993; Barnes et al., 2008). We model these trophic links using a feeding kernel (FK) that is further modified to give the feeding preference coefficient (eq. 8, $\phi$ ). Feeding kernels constitute the probability of a given predator ingesting prey of a particular size and can be highly variable, reflecting a great deal of measurement uncertainty and biological variability, with various studies employing gaussian, Laplace, and log-normal distributions (Law et al., 2009; Fuchs and Franks, 2010; Taniguchi et al., 2014; Heneghan et al., 2020). Here, we use the feeding kernel as a starting point to determine predator-prey feeding relationships, which are subject to additional tuning to achieve plankton distributions consistent with large-scale observational constraints. The feeding kernel $F K_{Z_{j}}$ is represented as a complementary error function: 


$$
F K_{Z_{j}}=\operatorname{Erfc}\left(\frac{\delta_{P_{i}, Z_{j}}}{\sqrt{2} \sigma_{Z_{j}}}\right)
$$

where $\operatorname{Erfc}(x)=1-\operatorname{Erf}(x)$, the standard error function:

$$
\operatorname{Erf}(x)=\frac{2}{\sqrt{\pi}} \int_{0}^{x} \exp -t^{2} d t
$$

and is closely related to the cumulative distribution function of the standard normal distribution.

Here, the numerator of the Erfc function is $\delta_{P_{i}, Z_{j}}$, which is the absolute value of the difference between the predator-prey size ratio and the optimal predator-prey size ratio for any given predator, $Z_{j}$ :

$$
\delta_{P_{i}, Z_{j}}=\left|\frac{E S D_{Z_{j}}}{E S D_{P_{i}}}-O p t_{Z_{j}}\right|
$$

where $E S D_{Z_{j}}$ and $E S D_{P_{i}}$ refer to the ESD (in mm) of the predator $Z_{j}$ and its prey, respectively, and $O p t_{Z_{j}}$ is the predator specific optimal predatorto-prey size ratio. Note that we have used the $P_{i}$ subscript here for simplicity, but the prey of $Z_{j}$ encompasses both phytoplankton and zooplankton prey. $O p t_{Z_{j}}$ varies from approximately 7.5 to 18 from the smallest to the largest zooplankton, and represents the phenomenon that the mean predator-to-prey size ratio will often increase as predator size increases (Hansen et al., 1994). The parameters that define $O p t_{Z_{j}}$ are given in Table 3.

Similarly, the width of the feeding kernel also increases as predator size increases, reflecting both the wider organism size ranges, varied prey capture strategies, and multiphagy of larger zooplankton (Hansen et al., 1994; Kiørboe, 2011). Here it is represented by $\sigma_{Z_{j}}$, which is in the denominator of eqn. 18, and is defined as $\sigma_{Z_{j}}=0.5 * O p t_{Z_{j}}$.

The feeding kernel as defined by the complementary error function has the property of being exactly 1 when $\delta_{P_{i}, Z_{j}}=0$, and then declines in a sigmoidal manner as the predator-to-prey ratio increasingly differs from the optimum. Put together over the whole range of predator-to-prey size ratios, the resultant curve increases to a point at the center (the optimum), and declines on either side (see Fig. 3f), resembling the Laplace (double exponential) distribution, which was used in Fuchs and Franks (2010). It is important to note here that the exact shape of the feeding kernel is secondary relative to the following adjustments to the predator-prey feeding preference coefficient, as 
they allowed us to tune this highly sensitive but poorly constrained grazing term to achieve plankton distribution patterns consistent with large-scale observational constraints.

Building upon this basic kernel formulation, we made several adjustments to model predator prey interactions to improve the representation of the model plankton community. First, we increased microzooplankton grazing on picoplankton relative to the value in the feeding kernel. The increased grazing accounts for unresolved grazing by heterotrophic nanoflagellates, and allows for a higher stability in picoplankton populations. Second, we increased grazing on small diatoms, kept medium diatoms the same, and decreased the grazing on large diatoms. The increase in grazing on small diatoms was necessary to provide a strong top-down control on the abundance of fast growing small diatoms. The reduced grazing on larger diatoms accounts for their ability to form colonies and/or frustules to reduce losses to predation (Oostende et al., 2018). Third, zooplankton production rates were lower than estimated values (Landry and Calbet, 2004), so we decreased zooplankton grazing on other zooplankton to increase zooplankton production. Fourth, we also increased grazing on the small implicit calcifying mixed phytoplankton group to increase zooplankton production and at the same time reduce their high abundance in subpolar regions. Fifth, to increase mesozooplankton production, we decreased microzooplankton grazing on small diatoms, to allow mesozooplankton to take advantage of diatom blooms especially in very productive regions of the ocean.

To ensure ingestion does not exceed maximum ingestion for a particular predator, the feeding kernel values were normalized by predator, such that the sum of all feeding kernel values per predator equalled 1. The individual feeding kernel values per predator-prey pair then modified predator ingestion rates (eq. 8).

\subsubsection{Zooplankton egestion, metabolism, and mortality}

Of the ingested prey carbon, $65 \%$ is assimilated into the predator biomass, and $35 \%$ is egested via sloppy feeding and fecal pellet production. The partitioning of the egestion into sinking particulate organic carbon (POC), semi-labile dissolved organic carbon (DOC), and highly labile DOC (which is instantly transformed to dissolved inorganic carbon, or DIC) varies by zooplankton size and phytoplankton prey type. The flux into sinking POC $\left(\rho^{P O C}\right)$ increases with zooplankton size. However, there is no distinction in the sinking speed of detritus by size. We used the ballast model of Armstrong 
Table 3: Size-dependent zooplankton biological parameters and scaling coefficients $(\mathrm{t}=$ $\left.\alpha V^{\beta}\right)$.

\begin{tabular}{|c|c|c|c|c|}
\hline \multirow[t]{2}{*}{ Parameter } & \multirow[t]{2}{*}{ Symbol } & \multicolumn{2}{|c|}{ Zooplankton } & \multirow[t]{2}{*}{ Units } \\
\hline & & $\alpha$ & $\beta$ & \\
\hline Maximum ingestion rate & $\iota_{j}^{\max }$ & 4.3 & -0.63 & $\mathrm{~d}^{-1}$ \\
\hline Quadratic mortality & $a_{j}$ & 0.21 & 0.58 & $m^{3} \mathrm{mmol} C^{-1} \mathrm{~d}^{-1}$ \\
\hline Zooplankton linear mortality & $m_{j}$ & 0.11 & -0.63 & $d^{-1}$ \\
\hline Optimal predator to prey-ratio & $O p t_{Z_{j}}$ & 12.9 & 0.53 & unitless \\
\hline
\end{tabular}

et al. (2002) to distinguish between sinking speeds for ballast minerals (silicate, biogenic calcium carbonate $\left(\mathrm{CaCO}_{3}\right)$, and mineral dust). The routing of ingestion to POC ranges from $0 \%$ for microzooplankton feeding on picoplankton to $35 \%$ for large mesozooplankton feeding on large diatoms. The remainder of the egestion losses not going to POC are partitioned to DOC $\left(\rho^{D O C} ; 25 \%\right)$ and DIC $\left(\rho^{D I C} ; 75 \%\right)$.

In MARBL-SPECTRA, we distinguish between zooplankton ingestionbased (active) respiration and biomass-based (basal) respiration. Active respiration is a fixed fraction of ingestion (35\%), but biomass-specific basal respiration decreases with size (Kiørboe and Hirst, 2014). Similar to the specific ingestion rate (Section 2.3.1), the biomass-specific linear mortality $\left(m_{j}\right)$ is temperature-dependent and decreases with body size with a $\beta$ of 0.25 (Hansen et al., 1997; Kiørboe and Hirst, 2014) and $\alpha$ of $0.12 \mathrm{~d}^{-1}$. These scaling relationships were converted to be scaled with volume with a $\beta$ of -0.63 and $\alpha$ of $0.11 \mathrm{~d}^{-1}$.

Zooplankton mortality due to predation by other zooplankton is resolved in the model in the lower size classes, becoming progressively unresolved with increasing size class. To account for the unresolved predation by higher trophic levels (fish, carnivorous jellies, marine mammals), the zooplankton quadratic mortality $\left(a_{j}\right)$ increases with biovolume with a $\beta$ of 0.21 and $\alpha$ of $0.58 \mathrm{~m}^{3}$ mmol $\mathrm{C}-1 \mathrm{~d}^{-1}$. We increased the quadratic mortality for largest mesozooplankton by a factor of 4 because to account for higher level grazing. The fraction of zooplankton quadratic mortality fluxing into particulate and dissolved organic matter pools depends on diet and organisms size. With a greater proportion of large zooplankton mortality being transferred to particulate organic matter pools compared to smaller zooplankton. 

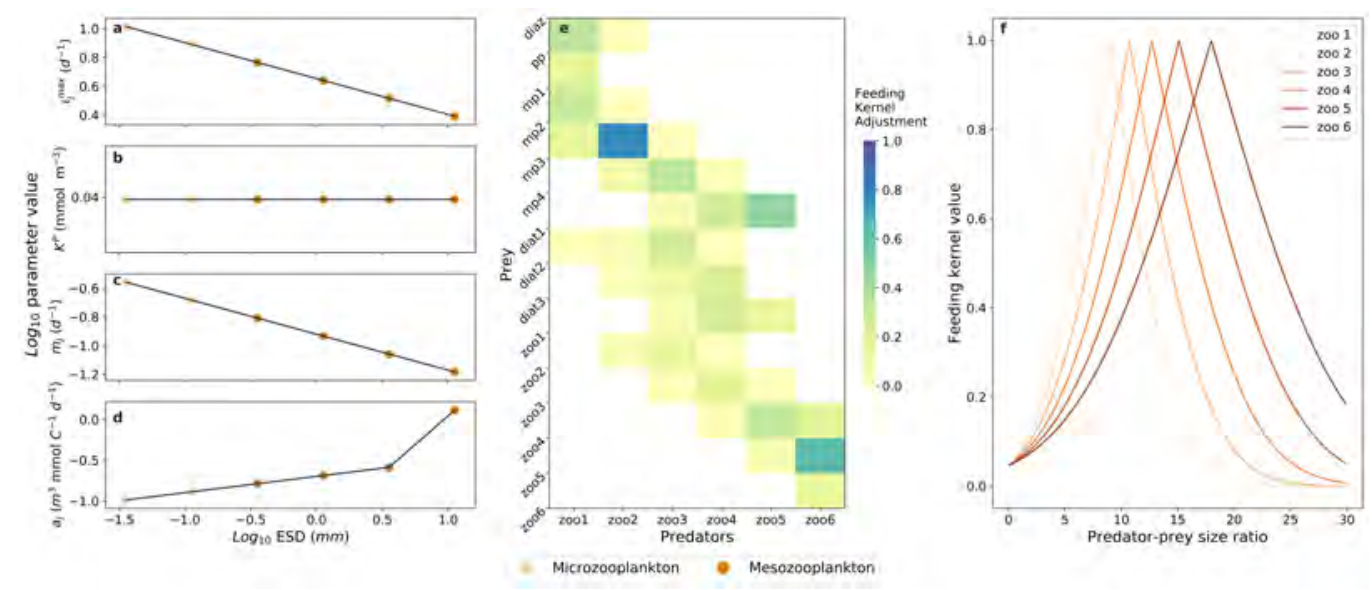

Figure 3: Zooplankton parameters. Relationships for microzooplankton $(<0.2 \mathrm{~mm}$ ESD) (light orange) and mesozooplankton ( $>0.2 \mathrm{~mm}$ ESD) (dark orange) between equivalent spherical diameter (ESD) and a) maximum zooplankton ingestion rate $\left.\left(\iota_{j}^{\max }\right), \mathrm{b}\right)$ zooplankton grazing half saturation constant for grazing $\left(K^{P}\right)$, c) linear mortality $\left(m_{j}\right)$, and (d) quadratic mortality $\left(a_{j}\right)$ (representing predation by higher trophic levels). e) Maximum grazing rates between predator and prey pairs and f) Value of the feeding kernel, which is then modified to give the feeding preference coefficient. The mean and width of the feeding kernel increases as zooplankton sizes increase.

\subsection{Model Calibration}

Many of the parameters required to simulate planktonic foods webs are difficult to measure directly, yet are highly important to simulate carbon and energy flow patterns (Stock and Dunne, 2010). In order to produce a balanced ecosystem, two main calibrations were done. First, the zooplankton loss terms (linear and quadratic mortality) were calibrated to preserve global totals of zooplankton production while largely maintaining allometric trait relationships across size classes (Kiørboe and Hirst, 2014; Hansen et al., 1997). We increased the zooplankton quadratic mortality for the largest mesozooplankton by a factor of four to account for unresolved predation by higher trophic levels. Phytoplankton linear mortality and aggregation loss were also calibrated because these parameters are poorly constrained by observations. Instead of a single allometric scaling, linear mortality was set as a fraction of $P C_{i}^{r e f}$, with a factor of 0.02 for diatoms and 0.03 for all other phytoplankton. The lower linear mortality in diatoms provides an advantage over other phytoplankton and increased their global production. We also removed the allometric scaling of phytoplankton aggregation loss $\left(a_{i}\right)$ with 
body size to allow the same rate of aggregation loss for every phytoplankton.

Second, the grazing half-saturation prey concentration for zooplankton were calibrated to allow higher global total zooplankton production. These parameters are poorly constrained by observations (Hansen et al., 1997), but the values used (Table 3) still fall within the observed ranges in Hansen et al. (1997). Because grazing half-saturation constants have been shown to be independent of body size (Hansen et al., 1997), only one $K^{P}$ had to be calibrated, because it was used for every zooplankton.

\subsection{Physical Framework}

MARBL-SPECTRA builds from the default MARBL configuration in CESM2.1 (MARBL-CESM2.1) in terms of biogeochemistry, plankton interaction and transmission of light as described by tables and equations in Long et al. (2021). However, we have increased the number of plankton functional types and size classes to include greater diversity. Here we briefly provide an overview of MARBL-SPECTRA, and some more detailed description of the more complex ecosystem. More details and the full set of equations and parameters can be found in Long et al. (2021). MARBL runs within the ocean component of the Community Earth System Model version 2 (CESM 2.1) (Moore et al., 2013b; Gent et al., 2011), which is the Parallel Ocean Program, version 2 (Smith et al., 2010). The physical configuration used here is very similar to that in CESM1, and a detailed description and evaluation of the ocean general circulation model in previous versions of CESM is given by Danabasoglu et al. (2012). The model has a nominal horizontal resolution of $1^{\circ}$, with 60 vertical depth levels ranging in thickness from $10 \mathrm{~m}$ in the upper $150 \mathrm{~m}$ to $250 \mathrm{~m}$ in the deep ocean (Moore et al., 2013b). The sea-ice component (CICE) is described by Hunke et al. (2017).

MARBL-SPECTRA simulates 55 tracers, including 17 non-living tracers and 38 tracers associated with the plankton community. This includes 27 tracers associated with the nine phytoplankton size classes, with each phytoplankton C, Chl, and Fe tracked separated (Moore et al., 2001, 2004a). In addition, there are 3 phytoplankton Si tracers associated with the three diatom classes, as well as 2 phytoplankton $\mathrm{CaCO}_{3}$ tracers associated with the two implicit calcifiers that are part of the mixed phytoplankton classes. Constant stoichiometry was assumed for zooplankton, therefore only 6 zooplankton carbon tracers were included. The model simulates six dissolved organic matter pools, including semi-labile and refractory dissolved organic carbon, nitrogen, and phosphorus (Letscher and Moore, 2015; Letscher et al., 
2015). It also includes sinking particulate pools and an explicit simulation of the biogeochemical cycling of key elements (C, N, P, Fe, Si, O, plus alkalinity) (Moore et al., 2004a). Riverine nutrients (N, P, Si, Fe), dissolved inorganic carbon, alkalinity, and DOM fluxes are supplied to the CESM2 ocean model via the nutrient loading estimates from GlobalNEWS (Mayorga et al., 2010) and the Integrated Model to Assess the Global Environmental-Global Nutrient Model (IMAGE-GNM) (Beusen et al., 2015, 2016). The plankton community component is coupled with a carbonate chemistry module based on the Ocean Carbon Model Intercomparison Project (OCMIP)(Najjar et al., 1999), allowing dynamic computation of surface ocean $\mathrm{pCO}_{2}$ and air-sea $\mathrm{CO}_{2}$ flux.

MARBL-SPECTRA simulations are forced with the Common Ocean-Ice Reference Experiment (CORE-II) data set(Large and Yeager, 2009). The forcing period from 1948 to 2009 (62 years) underwent two repeating cycles. This differs from CORE-II protocol where forcing undergoes five repeating cycles (Griffies et al., 2009). A shorter integration does not provide a fully-equilibrated model solution in the deep ocean, but has been used for studying surface ocean dynamics (Stock et al., 2014b). Thus, by the end of the 62 year spin up time, surface biomass distributions are nearing an equilibrium state, even if deep ocean tracers may not be. We focus our analyses on the final 20 years of the simulation (1990-2009). Code for generating the namelist parameters for MARBL-SPECTRA are available at: https://github.com/jessluo/gen_spectra. The version of MARBL used for these simulations is available at: https://github.com/jessluo/MARBL/tree/spectra.

\section{Results}

\subsection{Biogeochemical comparisons}

MARBL-SPECTRA qualitatively captures large-scale global biogeochemical and ecological patterns evident in available observations. Simulated global annual mean marine NPP, POC export, and nitrogen fixation, averaged over the top $150 \mathrm{~m}$, are shown in comparison to empirical estimates in Table 4. For these metrics, the model falls within range of empirical estimates. The global total marine diatom production is $14 \mathrm{Pg} \mathrm{C} \mathrm{yr}^{-1}$, which is about $28 \%$ of total NPP and falls within estimated values (20-40\% of total NPP) (Nelson et al., 1995; Aumont et al., 2003). Global total zooplankton production is $12 \mathrm{Pg} \mathrm{C} \mathrm{yr}^{-1}$ (23\% of NPP), falling within empirical estimates 
Table 4: Global annual averages of marine net primary production (NPP), sinking POC flux, and nitrogen fixation, averaged over the top $150 \mathrm{~m}$.

\begin{tabular}{|llll|}
\hline \hline Biogeochemical field & Global average & Empirical estimate & Reference \\
\hline \hline NPP & $52 \mathrm{Pg} \mathrm{C} \mathrm{yr}^{-1}$ & $35-70 \mathrm{Pg} \mathrm{C} \mathrm{yr}^{-1}$ & (Carr et al., 2006) \\
POC flux & $6.8 \mathrm{Pg} \mathrm{C} \mathrm{yr}^{-1}$ & $4-12 \mathrm{Pg} \mathrm{C} \mathrm{yr}^{-1}$ & (Dunne et al., 2007; DeVries \\
& & & and Weber, 2017) \\
Nitrogen Fixation & $107 \mathrm{Tg} \mathrm{N} \mathrm{yr}^{-1}$ & $51-196 \mathrm{Tg} \mathrm{N} \mathrm{yr}^{-1}$ & (Luo et al., 2014; Tang et al., \\
& & & $2019 ;$ Wang et al., 2019; \\
& & Großkopf et al., 2012) \\
\hline
\end{tabular}

(21-25\% of NPP) (Landry and Calbet, 2004), with microzooplankton contributing $8.7 \mathrm{Pg} \mathrm{C} \mathrm{yr}^{-1}$ to overall zooplankton production, and the remainder $3.3 \mathrm{Pg} \mathrm{C} \mathrm{yr}{ }^{-1}$ coming from mesozooplankton production.

The model captures the large-scale surface (top $10 \mathrm{~m}$ ) $\mathrm{NO}_{3}$ (Fig. 4a-c), $\mathrm{PO}_{4}$ (Fig. 4d-f), and $\mathrm{SiO}_{3}$ (Fig. 4g-i) distributions, with low nutrient concentrations in the subtropical gyres and higher nutrient concentrations in subpolar and upwelling regions. Because the model simulation is 62 years, the global nutrient distributions are not likely to be in a time-average steady state, particularly in the deep ocean. Compared with the 2018 World Ocean Atlas (WOA18) macronutrient observations (Garcia et al., 2019) (Fig. 4b,e $\& \mathrm{~h}$ ), near-surface $\mathrm{NO}_{3}, \mathrm{PO}_{4}$, and $\mathrm{SiO}_{3}$ concentrations are slightly higher in the model, with a bias of $+0.50,+0.090$, and $-1.4 \mathrm{mmol} \mathrm{m}^{-3}$ respectively. For $\mathrm{NO}_{3}$ and $\mathrm{PO}_{4}$, the bias is greatest in the tropical Pacific Ocean. This could be due to a slightly lower export flux from the upper oceans, due to higher nutrient recycling in this region coming from the dominance of smaller phytoplankton (Fig. 8). $\mathrm{SiO}_{3}$ biases are highest in the Southern Ocean, potentially due to insufficiently vigorous diatom production depressing $\mathrm{SiO}_{3}$ consumption. In the subpolar North Pacific Ocean, the model shows lower $\mathrm{NO}_{3}, \mathrm{PO}_{4}$, and $\mathrm{SiO}_{3}$, compared to the WOA18 observations (Fig. $4 \mathrm{c}, \mathrm{f}, \mathrm{i}$ ). This underestimation of macronutrients in the North Pacific is likely due to insufficient vertical mixing in this region, with phytoplankton production utilizing surface nutrients faster than they can be replenished. Simultaneously, overproduction of diatoms, due to insufficient $F e$ limitation stimulates the utilization of nutrients, leading to under-representation of the high nitrate, low chlorophyll (HNLC) region of the sub-Arctic North Pacific. 

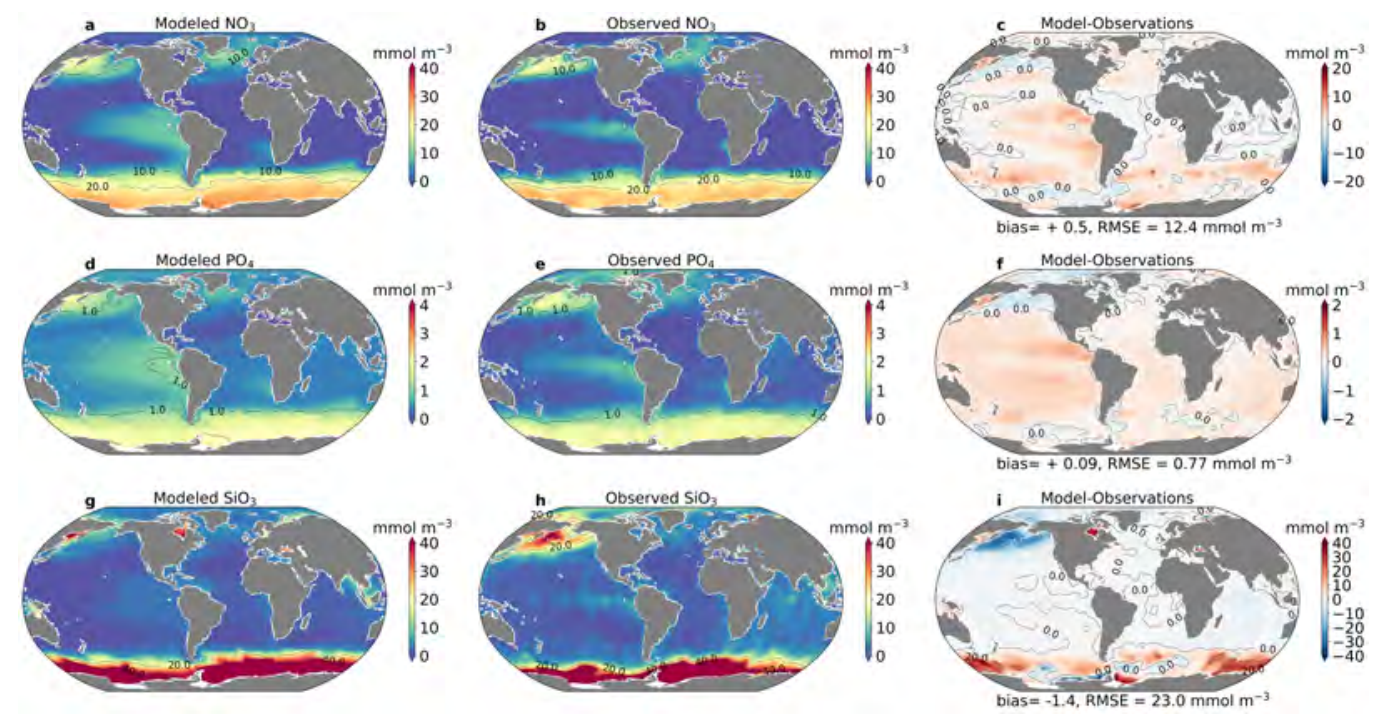

Figure 4: Macronutrients. Annual average modeled (a,d,g) and observed (b,e,h) surface (top $5 \mathrm{~m}$ ) concentrations of $\mathrm{NO}_{3}, \mathrm{PO}_{4}$ and $\mathrm{SiO}_{3}$ and their differences (Model-Observations; c,f,i). Observations are from the 2018 World Ocean Atlas release. (Garcia et al., 2019)

\subsection{Limitation of model phytoplankton growth}

Using phytoplankton-biomass-weighted means of the upper-ocean limitation terms, we show the nutrients most limiting growth for each phytoplankton in the model (Fig. 5). Phytoplankton growth is limited primarily by the availability of nitrate $\left(\mathrm{NO}_{3}\right)$ or Fe and regionally by $\mathrm{PO}_{4}$ (diazotrophs) and $\mathrm{SiO}_{3}$ (diatoms) (Fig. 5), consistent with previous modelling studies using CESM (Moore et al., 2013a; Long et al., 2021). The degree of growth limitation by nutrients becomes stronger as body size increases (Fig. 5). This occurs because smaller phytoplankton have greater capacity to acquire nutrients via diffusion relative to their nutrient demands (Edwards et al., 2012). Nutrient replete areas (white areas in Fig. 5) are characterized by where the concentration of nutrients is high enough to support growth rates $>90 \%$ of the maximum potential growth rate. For picoplankton, these occur in the equatorial upwelling region and the subpolar and polar regions (Fig. 5a). For diazotrophs, these occur in equatorial regions of the Atlantic and Indian Oceans, as well as the western Pacific (Fig. 5b). Diatoms and mixed phytoplankton are rarely nutrient replete due to their high nutrient requirements (Fig. 5c,d). In addition to these overall patterns, diazotrophs undergo stronger $\mathrm{PO}_{4}$ limitation in the North Atlantic due to enhanced $\mathrm{N}_{2}$ fixation 


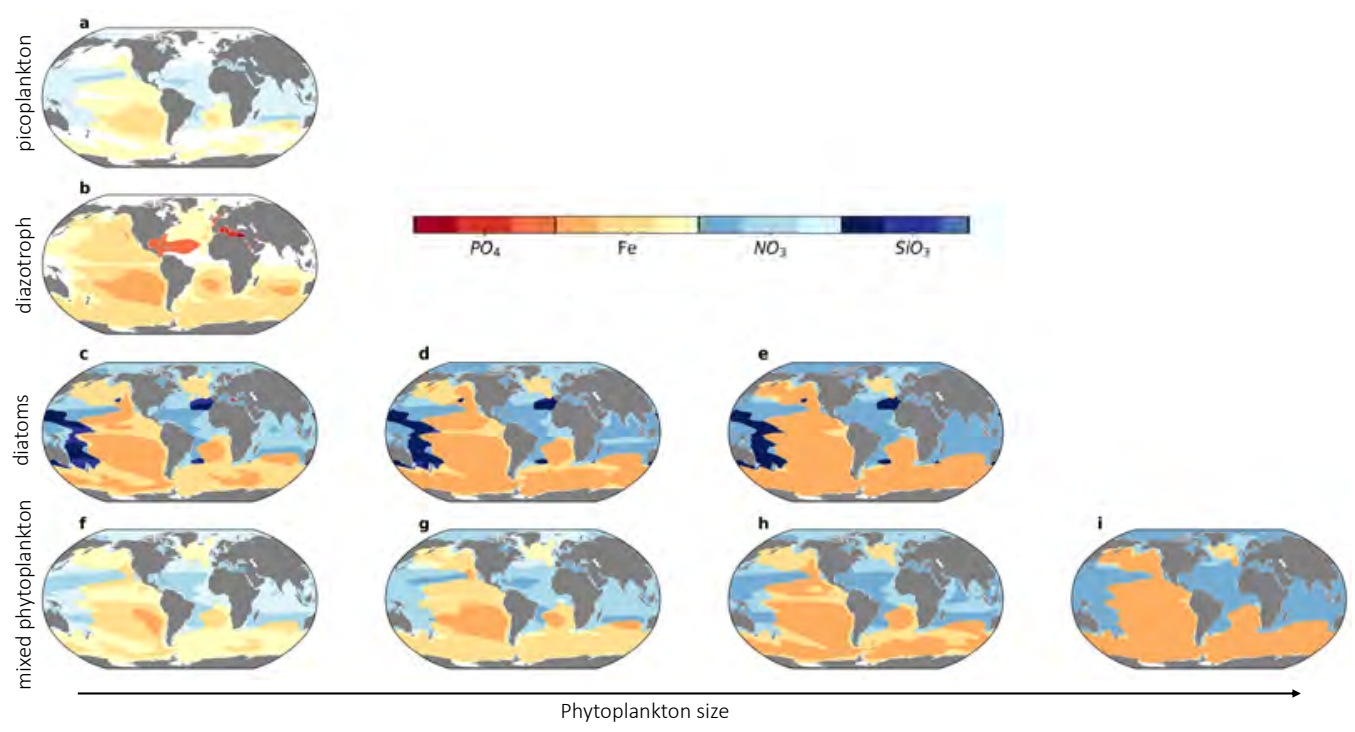

Figure 5: Phytoplankton nutrient limitation in top 100m. The nutrient most limiting phytoplankton growth over the 20 year climatology (January 1990- December 2009). Rows categorize phytoplankton by their functional group: (a) picoplankton, (b) diazotroph, (c) diatoms, and (d) mixed phytoplankton. Columns indicate relative phytoplankton size within each group, increasing from left to right.

\subsection{Chlorophyll}

Model annual-mean surface (top $10 \mathrm{~m}$ ) chlorophyll exhibits plausible spatial gradients tied to provision of nutrients to the ocean surface and good overall agreement with observations (Fig. 6). Surface chlorophyll observations were obtained from the Sea-viewing Wide Field-of-view Sensor(SeaWiFS) climatology from 1998-2009, which corresponds to the last twelve years of the CORE-II forcing dataset (Large and Yeager, 2009). Model chlorophyll is low in subtropical gyres due to wind-driven downwelling and low surface nutrient availability (Fig. 4a). In higher latitudes and upwelling areas, higher nutrient concentrations allow for higher chlorophyll concentrations (Fig. 6a). Model annual average chlorophyll generally exceeds observations in subtropical and temperate locations, while the model underestimates chlorophyll in the Arctic, Antarctic, and coastal upwelling regions (Fig. 6c). 

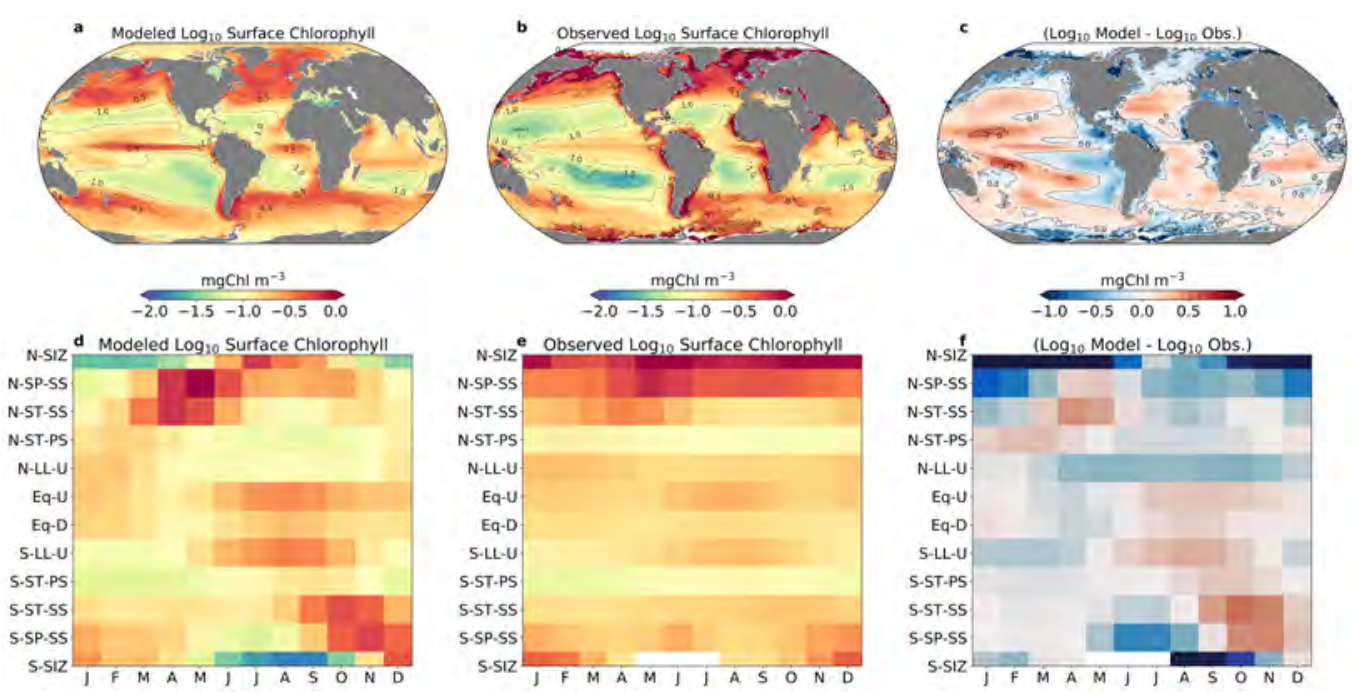

Figure 6: Surface (top $10 \mathrm{~m}$ ) chlorophyll concentration $\left(\mathrm{mg} \mathrm{Chl} \mathrm{m}{ }^{-3}\right)$. (a) Simulated annual-mean surface chlorophyll, (b) satellite-derived (SeaWiFS) estimate of annual-mean surface chlorophyll, (c) model - SeaWiFS, (d) mean monthly modeled surface chlorophyll by biomes; (e) mean monthly SeaWiFS surface chlorophyll by biomes; and (f) difference between model and observations on a monthly, per-biome basis. Refer reader to biome map, and say how they were calculated.

The positive chlorophyll bias in subtropical and subpolar seasonally stratified biomes of the northern hemisphere is due to an earlier than observed phytoplankton bloom that starts in March and ends around June, about a month earlier than the observed bloom in April through June (Fig. 6f). This is perhaps due to lower mesozooplankton biomass in the spring from lack of diaupasing zooplankton, yielding insufficient top-down control on phytoplankton and leading to an earlier spring bloom (Behrenfeld, 2014). The higher chlorophyll concentrations in the central Equatorial Pacific between July to November (Fig. 6f) are associated with higher nutrient delivery to the surface from the Equatorial upwelling zone. In the subtropical and subpolar Southern Hemisphere, a stronger bloom initiates sooner (September) than observational estimates (November/December) (Fig. 6f), leading to a positive bias in subtropical and subpolar seasonally stratified biomes of the Southern Hemisphere.

Vertical profiles of model chlorophyll show important biases compared with observations. Comparing vertical chlorophyll profiles of The Bermuda Atlantic Time-series Study (BATS), and the Hawaii Ocean Time-series (HOT) 
stations (Fig. S2), MARBL-SPECTRA simulates a shallower deep chlorophyll maximum (DCM) layer for BATS (60-80m) compared to HOT (70$100 \mathrm{~m})$. However, compared with observed values, MARBL-SPECTRA simulates DCMs that are too shallow for both of these regions. For instance, data from HOT and BATS indicates a DCM layer falling between 60-120m for BATS (Steinberg et al., 2001), and 100-150m for the HOT station (Letelier et al., 2004). The tendency of these deep chlorophyll maximum to be shallower than observations may be due do a variety of reasons, such as the lack of representation of low-light adapted ecotypes of picoplankton which are generally restricted to the deep euphotic zone (Moore et al., 2002; Johnson et al., 2006; Moore and Chisholm, 1999) contributing to the deep chlorophyll maximum. The under-representation of mixotrophy in the model could also contribute to this bias, as it has been found that the incorporation of mixotrophy in models has helped represent DCMs more accurately (Moeller et al., 2019).

\subsection{Phytoplankton biogeography}

The distribution of small, medium, and large phytoplankton in the model is consistent with satellite-derived size class estimates from Hirata et al. (2011). The small group includes the picoplankton (pp) and the smallest mixed phytoplankton (mp1), the medium group includes the smallest diatom (diat1), the diazotroph (diaz), and the medium mixed phytoplankton (mp2), and the large group includes the largest two diatoms (diat2, diat3) and the largest two mixed phytoplankton (mp3, mp4). The satellite algorithm used by Hirata et al. (2011) estimates the biomass of three phytoplankton size classes as microphytoplankton $(>20 \mu \mathrm{m})$, nanophytoplankton $(2-20 \mu \mathrm{m})$ and picophytoplankton $(<2 \mu m)$.

Small phytoplankton dominate the subtropical gyres with over $70 \%$ of the total $\mathrm{Chl}_{a}($ Fig. $7 \mathrm{c})$. These regions are characterized by strong vertical stratification and weak nutrient delivery to the surface. Here, small phytoplankton can outcompete larger phytoplankton due to their higher scaled nutrient and light affinities allowing them to maintain positive net growth at low nutrient concentrations compared to larger competitors (Edwards et al., 2012). Medium phytoplankton dominate in subpolar gyres, coastal upwelling zones, and equatorial upwelling regions where nutrient delivery is greater. Here, grazing pressure on small phytoplankton prevents small cells from consuming all resources and allows the medium phytoplankton to become established. The largest phytoplankton are found mainly in polar regions in the Arctic 

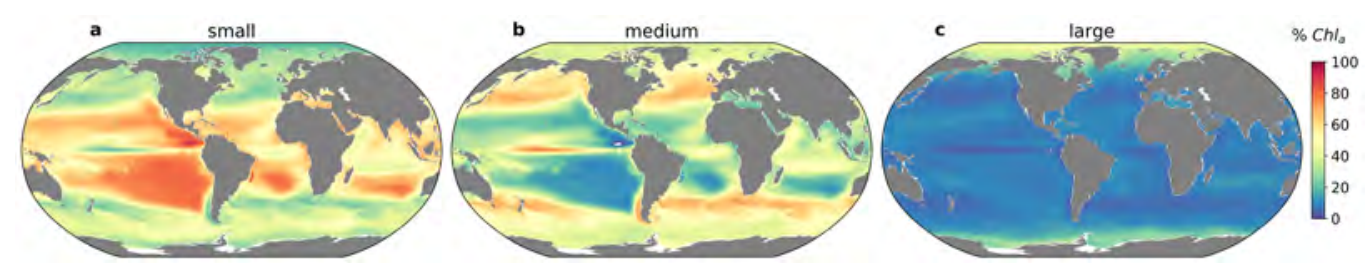

Figure 7: Phytoplankton size class biogeography. Percent of total chlorophyll in each size class: (a) Small phytoplankton (includes picoplankton and smallest mixed phytoplankton, (b) Medium phytoplankton (includes the smallest diatom, the second smallest mixed phytoplankton, and the diazotroph), and (c) Large phytoplankton (includes the two largest mixed phytoplankton, and the largest two diatoms on the model).

and Southern Oceans, where the balance between growth and predation on small and medium phytoplankton, together with lower light affinities, allows these larger phytoplankton to survive.

Diatoms illustrate the importance of modelling different size classes within each phytoplankton functional type. Diatoms are found from the tropics to the poles, but are most abundant in polar to temperate, nutrient-rich regions, where silicic acid and other nutrients are not limiting. However, the distribution of modeled diatoms varies by size and associated organism traits (Fig. S3g-i). Compared with other diatoms, the smallest diatom has a higher specific growth rate, lower nutrient half-saturation constants, and higher affinity for light (Fig. 2), but also proportionally higher losses to mortality and grazing (Fig. 2; 3). Small diatoms are most abundant in coastal, equatorial upwelling, and subpolar regions (Fig. S3g). Larger diatoms have somewhat lower growth rates, weaker nutrient uptake abilities, and lower light affinity $\alpha_{i}^{C h l}$, but lower mortality and losses to grazing (Fig. 2; 3). Large diatoms, therefore, are most abundant in subpolar and polar regions (Fig. S3i). The ability to model different size classes within each functional group allows us to observe these patterns that would otherwise not be resolved.

The phytoplankton size abundance relationship is a general descriptor of phytoplankton community size structure, and plays a fundamental role in pelagic ecosystems as it determines the trophic organization of plankton communities and, hence, the biogeochemical functioning of the ecosystem (Legendre and Rassoulzadegan, 1996; Kiørboe, 1993). The relationship between phytoplankton abundance and cell volume $(V)$ follows a power law, $N=\alpha V^{\beta}$, where $N$ is the cell density and $\alpha$ is the intercept of the resulting linear regression. The size-scaling exponent, $\beta$, is a descriptor of commu- 
nity size structure (Marquet et al., 2005) and generally takes values between -1.3 and -0.6 (Huete-Ortega et al., 2012). The slope of the size abundance relationship was calculated by plotting the logarithmic abundances of all phytoplankton size classes as a function of their volume.

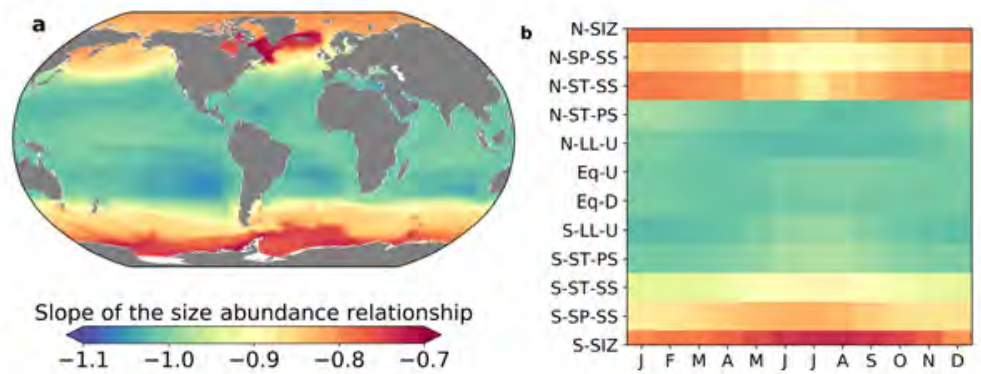

Figure 8: Slope of the size abundance relationship. (a) The annual averaged surface slope of the size abundance relationship, and (b) mean monthly surface slope of the size abundance relationship by biomes (Fig. S1) over the period 1990-2009. More negative slopes are seen in the stratified waters of low-latitude, open-ocean environments, where small cells account for most of the biomass, and less negative slopes appear in more nutrient-rich, productive regions, where larger cells generally constitute a greater fraction of total biomass than in lower nutrient regions.

Overall, MARBL-SPECTRA captures the horizontal gradients in size driven by the provision of nutrients to the ocean surface (Barton et al., 2013). Locations with more negative slopes tend to have relatively few large phytoplankton present, whereas a less negative slope indicates the presence of proportionally more large phytoplankton(Cermeño et al., 2006). In MARBLSPECTRA (Fig. 8b), the most negative slopes (between -1.2 and -0.9) occur in the permanently stratified oligotrophic subtropical gyres where small phytoplankton dominate and large cells are scarce (Fig. 7). The highest contribution of small cells is especially seen during the boreal and austral summer of permanently stratified subtropical gyres, and lower latitude upwelling regions (Fig. 8b). The least negative slopes $(>-0.9)$ are found in more productive regions of the ocean, like the subpolar and polar regions where larger phytoplankton have a higher contribution to total phytoplankton biomass (Fig. S3). Seasonally, less negative slopes are found during the boreal and austral Winter of the seasonal ice zone, and the northern seasonally stratified subpolar gyre (Fig. 8b). 


\subsection{Zooplankton production}

MARBL-SPECTRA's global zooplankton production is mostly composed of microzooplankton. Approximately $73 \%$ of the total zooplankton production comes from microzooplankton $(<200 \mu \mathrm{m}$ ESD), represented by the two smallest zooplankton groups. These zooplankton dominate the grazing on picoplankton and small mixed phytoplankton. As a result, the microzooplankton are broadly distributed and are most abundant in the oligotrophic and subpolar regions (Fig. S4a,b). MARBL-SPECTRA simulates crossbiome patterns in mesozooplankton biomass, with the highest values in the North Pacific, the equatorial Pacific, and coastal upwelling regions (Fig. 9a).

We compare model zooplankton biomass to observations from the NOAA COPEPOD global zooplankton database (https://www.st.nmfs.noaa.gov/copepod/), of which the global mesozooplankton carbon biomass dataset is the most relevant and accessible (Moriarty and O'Brien, 2013), for model output comparison. However, since the COPEPOD database compiles measurements collected by net-tows of epipelagic mesozooplankton captured primarily using large, $300 \mu \mathrm{m}$ nets that under sample small mesozooplankton (Moriarty and O'Brien, 2013; Landry et al., 2001; O'Brien, 2005)), we only used the three largest mesozooplankton (zoo4-zoo6) for our model-data comparison. Additionally, because the COPEPOD database includes more samples during summer months, we only compared with summer months of each hemisphere (Fig. 9a,b). When comparing modeled and observed mesozooplankton across biomes (Fig. 9c-e), we excluded biomes containing less than $25 \%$ of observations at each month. MARBL-SPECTRA's annual average mesozooplankton biomass (only accounting for grid cells with observations) averages $2.7 \mathrm{mg}$ $\mathrm{C} \mathrm{m}^{-3}$, compared with COPEPOD's annual average of $4.7 \mathrm{mg} \mathrm{C} \mathrm{m}^{-3}$. The discrepancy from the model and observations comes from coastal upwelling regions in the model having lower biomass than observed in the COPEPOD database. Mesozooplankton biomass is lowest in the Southern Ocean and the sub-Arctic North Atlantic (Fig. 9a). Compared with the COPEPOD database observations, MARBL-SPECTRA overestimates mesozooplankton biomass in subtropical regions (Fig. 9e). This can be seen especially in gradients between coastal and offshore regions (e.g. near California Current), where high mesozooplankton production near the coast does not decrease to considerably lower values as you move to the oligotrophic regions in the model output. Thus, MARBL-SPECTRA captures basin-scale gradients in zooplankton biomass, but the dynamic range in the model is reduced compared with observations. 


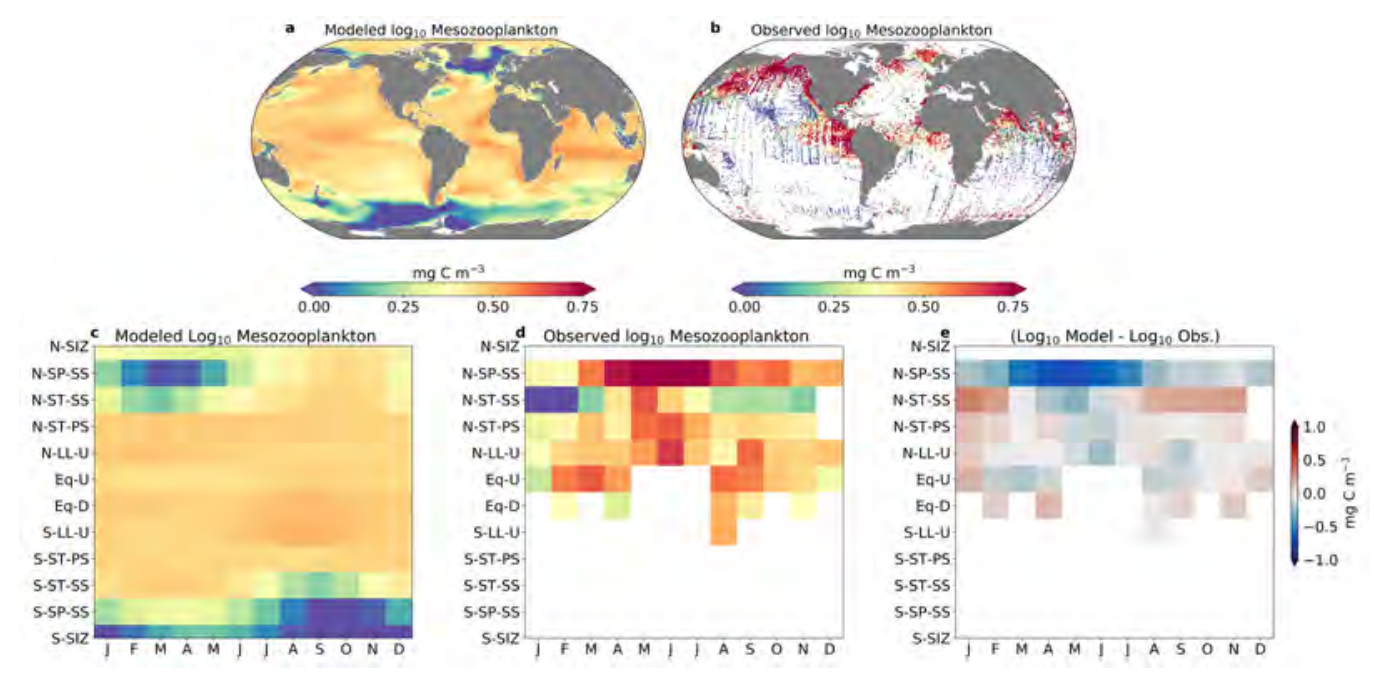

Figure 9: Mesozooplankton biomass. (a) Modeled annual mean mesozooplankton biomass $\left(\mathrm{mg} \mathrm{C} \mathrm{m}{ }^{-3}\right.$ ) over the top $150 \mathrm{~m}$ (only including largest three mesozooplankton (zoo4 zoo6), compared with (b) observed annual average mesozooplankton biomass using the COPEPOD database ( $\mathrm{mg} \mathrm{C} \mathrm{m}^{-3}$ ) (Moriarty and O'Brien, 2013). (c) Mean monthly modeled surface mesozooplankton biomass by biomes; (d) mean monthly COPEPOD mesozooplankton biomass by biomes (only showing biomes that have more than $25 \%$ of data at each month); and (e) difference between model and observations.

Model mesozooplankton biomass in MRABL-SPECTRA display a weaker spatial dynamic range compared to observations. The strong negative bias of modeled mesozooplankton (Fig. 9e) in the subpolar and subtropical seasonally stratified biomes of the Northern Hemisphere comes from the underestimation of mesozooplankton biomass in the sub-Arctic North Atlantic, along with a 3-4 month delay in the zooplankton bloom (Fig. 9e). MARBLSPECTRA does not resolve zooplankton life histories, including dormancy or diapause, which may contribute to these discrepancies. Due to limited observations, we are unable to diagnose seasonal zooplankton biomass patterns in poorly-sampled regions of the ocean (Fig. 9d). However, MARBLSPECTRA simulates a Southern Hemisphere subpolar zooplankton bloom from December to March and the subtropical seasonally stratified bloom in the Southern Hemisphere from October to June (Fig. 9c). The low latitude upwelling region in the Southern Hemisphere shows a model mesozooplankton bloom from June to October, similar to a shorter one observed in the equatorial upwelling region from June to September. 


\subsection{Generation time}

MARBL-SPECTRA simulates plankton generation times and allows us to analyze their influence by organism size, temperature, and latitude. Plankton generation time was calculated as the ratio of depth-integrated biomass $\left(\mathrm{mmol} \mathrm{m} \mathrm{m}^{-2} \mathrm{C}\right)$ over production $\left(\mathrm{mmolC} \mathrm{m}^{-2} \mathrm{~d}^{-1}\right)$, averaged over the top $150 \mathrm{~m}$. The global average generation time for phytoplankton increased with body size, ranging from a few days for picoplankton to a few months for the largest mixed phytoplankton (Fig. 10a). Global average zooplankton generation times ranged from about a week for the smallest microzooplankton to a few months for the largest mesozooplankton. However, there are considerable regional variations in generation time. The longest generation times reached almost a year for the largest mixed phytoplankton and almost two years for mesozooplankton near the poles, with the shortest generation times found in the tropics (Fig. SI S7,S8). These variations in generation time reflect body size and temperature effects (Gillooly et al., 2001; Gillooly, 2000; Gillooly et al., 2002), although, consumption, respiration, predation, and mortality are also of influence. Generation times for some copepod species have been observed to reach up to 3-4 years (Hirche, 1997). However, MARBL-SPECTRA does not resolve zooplankton life histories such as diapause, which limits generation times for some mesozooplankton especially in polar regions.

\subsection{Trophic Scaling}

The model indicates not only zooplankton biomass and generation length, but food chain length and zooplankton trophic level. Using the grazing fluxes between predators and prey, we calculated the trophic level for each zooplankton by assigning a value depending on their prey. For example, zooplankton in the second trophic level are those who only feed on phytoplankton, with additional trophic levels beyond this added depending on the trophic level of zooplankton they eat as prey at each grid cell. Model simulations show average zooplankton trophic levels to be highest in the oligotrophic subtropical gyres and lowest in polar regions around the Southern Ocean and the Arctic Ocean (Fig. 10b \& Fig. S6). Low productivity regions of the ocean tend to have longer, less efficient food chains, suggesting a greater flow of energy and carbon through the microbial loop (Steinberg and Landry, 2017). Productive regions with lower zooplankton trophic levels tend to have shorter, more efficient food chains (Fig. 10b), suggesting a more efficient energy transfer towards upper food web levels. Thus, for each given zooplankton size class 

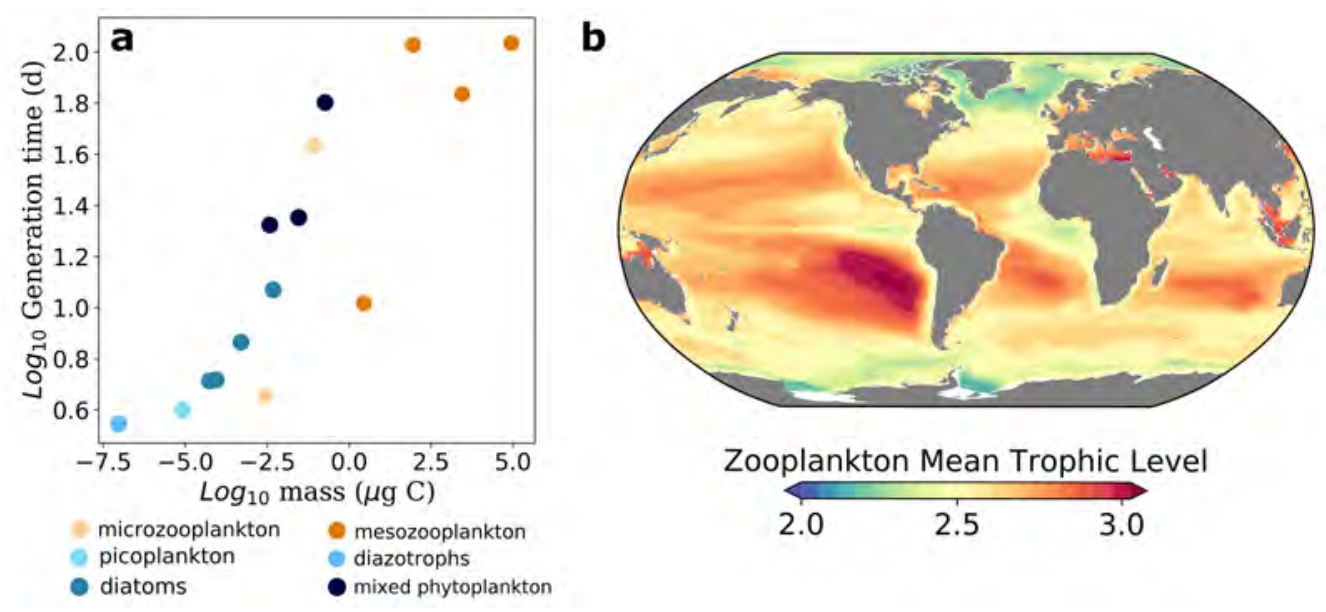

Figure 10: Predator-prey generation time and trophic dynamics. (a) Annual global average generation time averaged over the top $150 \mathrm{~m}$ in days for each phytoplankton (blue), and zooplankton (orange) size class, as a function of organisms body mass (units). (b) Zooplankton annual mean trophic level over the top $150 \mathrm{~m}$. A trophic level of 2 indicates an entirely herbivorous zooplankton feeding on primary producers. A trophic level 3 indicates secondary consumers, which are carnivorous zooplankton that eat herbivores.

(Fig. S6), the average trophic level for each type of model zooplankton increased in the low nutrient, subtropical gyres, illustrating the predominance of lengthened food webs in those regions. In contrast, the Southern Ocean and the Arctic Ocean are not characterized by high trophic levels but are areas of elevated zooplankton biomass, especially large mesozooplankton.

\subsection{Zooplankton to phytoplankton biomass ratio}

MARBL-SPECTRA resolves spatial and temporal variations in the biomass pyramid in lower trophic levels of marine ecosystems, and consequently can provide mechanistic insights on factors regulating this structure. Regions of high phytoplankton and zooplankton biomass are concentrated in subpolar and coastal regions, whereas the oligotrophic gyres support much lower total biomass (Fig. S5a,b). The zooplankton to phytoplankton biomass ratio is at or below 1 in most of the ocean, consistent with observations from Irigoien et al. (2004); Gasol et al. (1997), and modelling results in marine (Vallina et al., 2014) and lake systems (Yuan and Pollard, 2018). Z:P biomass ratios are also shown to vary seasonally, in this case focusing on data from Northern Hemisphere subpolar and polar regions $\left(35^{\circ} \mathrm{N}-90^{\circ} \mathrm{N}\right)$. Here, the highest 
$\mathrm{Z}: \mathrm{P}$ ratios occurred in winter months, driven by declines in phytoplankton biomass (Fig. 11c).
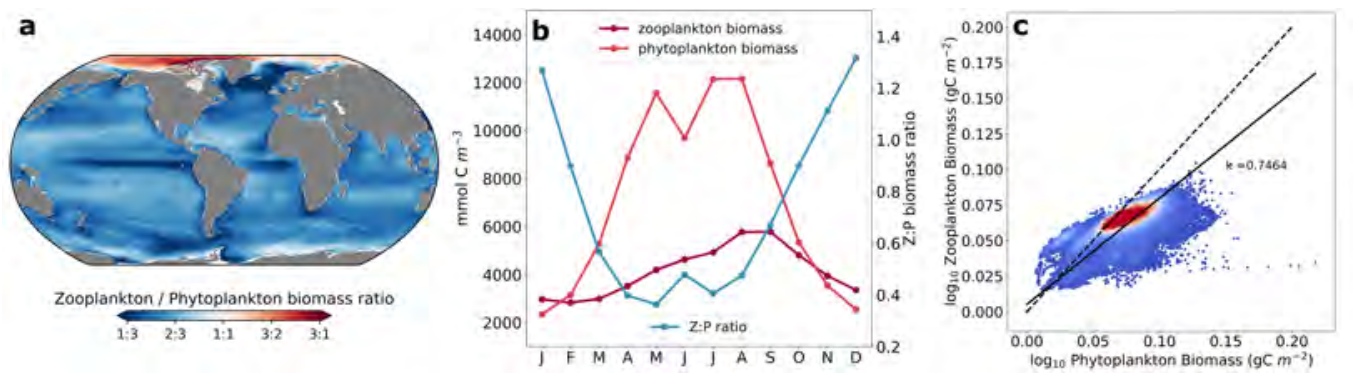

Figure 11: Predator-prey biomass ratios. (a) Global map of the zooplankton to phytoplankton biomass ratio, showing the depth integrated annual mean over the top $150 \mathrm{~m}$. (b) Seasonal zooplankton biomass (dark pink), phytoplankton biomass (light pink), and zooplankton to phytoplankton biomass ratio (blue) of polar and subpolar regions in the Northern Hemisphere $\left(35^{\circ} \mathrm{N}-90^{\circ} \mathrm{N}\right)$. (c) $\log _{10}$ zooplankton and phytoplankton biomass relationship integrated over the top $150 \mathrm{~m}$. The dashed black line represents the 1:1 line, and the solid black line represents the least squares line of best fit, which has an exponent of 0.7464 in bold (with $95 \% \mathrm{CI}$ ).

The model indicates that as phytoplankton biomass increases, so too does zooplankton biomass. However, the rate of increase in zooplankton biomass is less than for phytoplankton biomass, such that the slope of the $\log _{10^{-}}$ $\log _{10}$ relationship between model phytoplankton and zooplankton biomass is approximately 0.75 (Fig. 11b). Our results are consistent with a $3 / 4$ scaling exponent between prey and predator biomass observed by Hatton et al. (2015). In regions of low phytoplankton biomass, such as the oligotrophic gyres, Z:P ratios are close to 1:1, suggesting a tight and efficient coupling between small phytoplankton and their microzooplankton consumers. In regions of higher phytoplankton biomass, Z:P ratios are lower, suggesting a greater degree of decoupling between predators and prey.

One exception from this overall relationship is the Arctic Ocean, which has much higher Z:P ratios, in some cases approaching 3:1. Here, the balance between strong seasonal bottom-up (light and temperature) controls and intense grazing pressure in these regions might explain the high Z:P biomass ratios.

\subsection{Plankton phenology}

The enhanced plankton community in MARBL-SPECTRA provides a mechanistic representation of the function and dynamics of plankton phenol- 

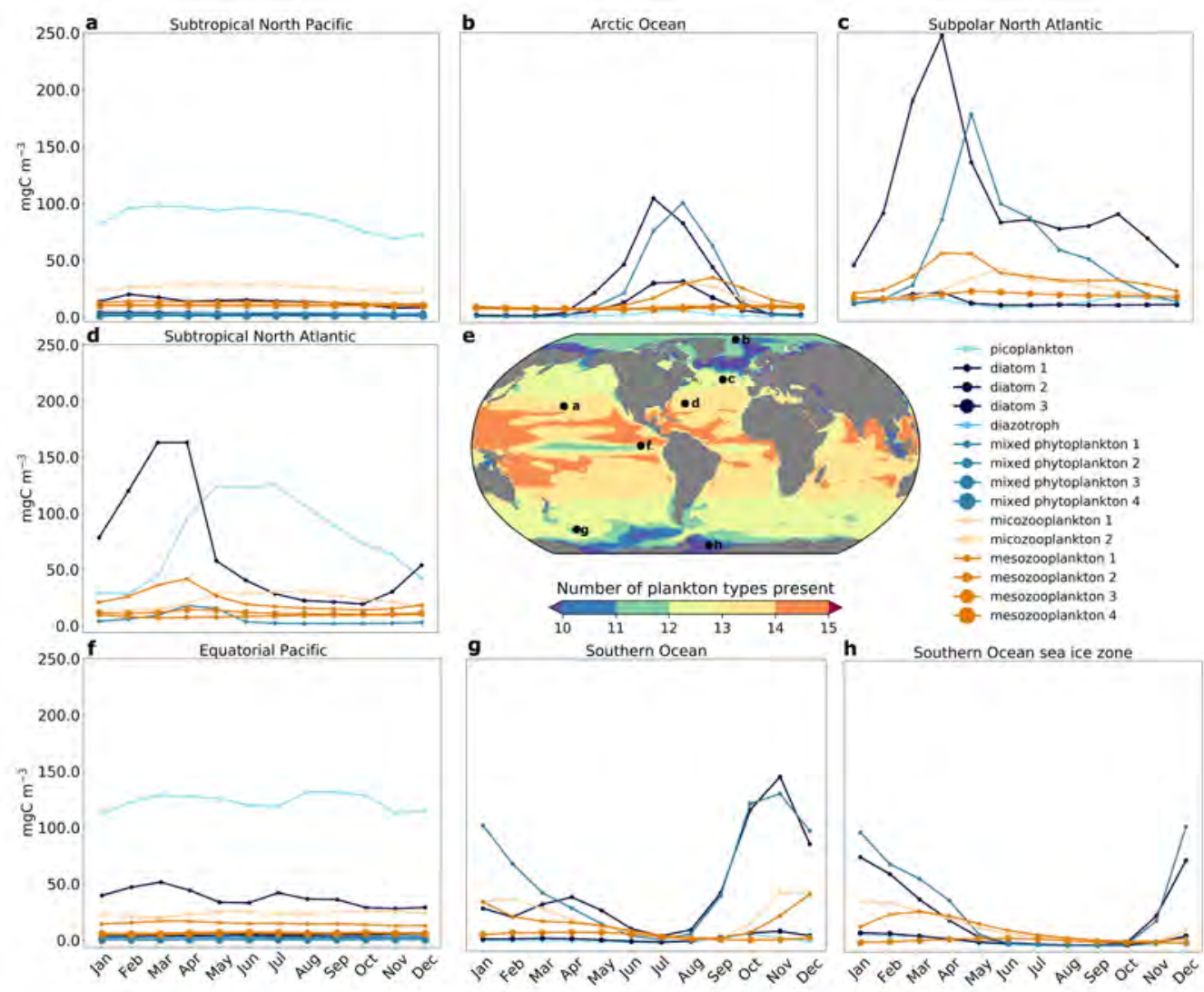

Figure 12: Plankton phenology. Average number of plankton present at a level more than $1 \%$ of the total plankton biomass for a given grid cell at any time of the year (e). Seasonal cycles for phytoplankton (blue) and zooplankton (orange) in a $5^{\circ}$ by $5^{\circ}$ region in the (a) Subtropical North Pacific $\left(47-51^{\circ} N, 165-160^{\circ} W\right)$, (b) Arctic Ocean $\left(78-83^{\circ} N, 1-6^{\circ} W\right)$, (c) Subpolar North Atlantic $\left(45-50^{\circ} N, 27-32^{\circ} W\right)$, (d) Subtropical North Atlantic $\left(78-83^{\circ} N, 1-6^{\circ} W\right)$, (f) Equatorial Pacific $\left(2^{\circ} N-2^{\circ} S, 97-101^{\circ} W\right)$, (g) Southern Ocean $\left(47-61^{\circ} \mathrm{S}, 171-175^{\circ} \mathrm{W}\right)$, and $(\mathrm{h})$ Southern Ocean sea ice zone $\left(66-70^{\circ} \mathrm{S}, 38-42^{\circ} \mathrm{W}\right)$. The seasonal cycles are calculated from 20 year (1990-2009) biomass climatologies from the model.

ogy, where the phenology of model plankton is tied to their body size, traits, and interactions. Here, we show the seasonal cycle of biomass for seven $5^{\circ}$ by $5^{\circ}$ locations in the global ocean (Fig. 12). While the details of a given site may differ between the model and observations for a range of reasons, the model simulates a seasonal succession at each location tied to nutrient delivery, temperature, light availability, and grazing pressure. 
For example, in the subtropical North Pacific $\left(47-51^{\circ} N, 165-160^{\circ} \mathrm{W}\right.$; Fig. 12a), low nutrient availability leads to picoplankton dominance throughout the year. Strong grazing pressure from small microzooplankton together with low nutrient delivery allows for the dominance of relatively small phytoplankton. The Equatorial Pacific $\left(2^{\circ} N-2^{\circ} S, 97-101^{\circ} W\right.$; Fig. 12f) is similarly dominated by picoplankton throughout the year with weak seasonality, however shows a higher contribution of small diatoms due to higher nutrient inputs from Equatorial upwelling (Fig. 4). Conversely, in the subpolar North Atlantic region $\left(45-50^{\circ} \mathrm{N}, 27-32^{\circ} \mathrm{W}\right.$; Fig. 12c), MARBL-SPECTRA simulates a Spring bloom dominated by small diatoms and mixed phytoplankton. The bloom decreases with the emergence of small microzooplankton and mesozooplankton grazing, followed by the development of a fall bloom composed of small diatoms. The Subtropical North Atlantic $\left(78-83^{\circ} N, 1-6^{\circ} \mathrm{W}\right.$; Fig. 12d), shows a similar, but weaker spring bloom dominated by the small diatoms, decreasing with the emergence of mesozooplankton grazing. This bloom is followed by a longer fall and summer picoplankton bloom. In the Southern Ocean $\left(47-61^{\circ} \mathrm{S}, 171-175^{\circ} \mathrm{W}\right.$; Fig. 12g), small diatoms and mixed phytoplankton drive a late Spring/early austral Summer bloom due to high nutrient supply. A similar but shorter bloom occurs in the Southern Ocean sea-ice zone $\left(66-70^{\circ} \mathrm{S}, 38-42^{\circ} \mathrm{W}\right.$; Fig. 12h) driven by the small diatoms and mixed phytoplankton. In the Arctic Ocean $\left(78-83^{\circ} N, 1-6^{\circ} \mathrm{W}\right.$; Fig. 12b), small and medium diatoms and small mixed phytoplankton drive a boreal Summer bloom decreasing with the emergence of microzooplankton and mesozooplankton grazing.

Overall, MARBL-SPECTRA can simulate phenology and succession in a more diverse fashion than models with fewer taxa. We calculated the total number of phytoplankton and zooplankton taxa present at greater than $1 \%$ of total biomass of phytoplankton and zooplankton in each month of the year, and averaged this over all months, to find the averaged number of model species present at any time of year. The highest average number of plankton present contributing to more than $1 \%$ of plankton biomass are seen in the subtropical gyres, especially near coastal boundary currents (Fig. 12e). The weak seasonality, and high contribution of small phytoplankton and microzooplankton throughout the year might contribute to this greater number of plankton present in the subtropical gyres compared to other regions. Meanwhile, the higher nutrient concentration in the Equatorial upwelling region, drivers a the opportunist small diatoms to dominate most of the plankton biomass decreasing the number of plankton types present (Fig. 12e \& Fig. 
S3). Polar regions display a lower average number of plankton types present throughout the year due to strong seasonality, and higher dominance of larger plankton types (Fig. 12e \& Fig. 8).

\section{Discussion}

\subsection{Significant model advances}

MARBL-SPECTRA is a plankton community model that expands on plankton functional types and size classes compared to previous CESM plankton community models. The union of functional type modelling with sizeresolved, trait-based models provides a tractable approach to simulate the critical biogeochemical cycles mediating the large-scale structure of carbon and nutrient distributions and the complex and nuanced variation of planktonic ecosystems controlling trophic energy transfer. MARBL-SPECTRA provides a framework to simulate seasonal and regional changes in phytoplankton phenology and diversity and their roles in ecosystem functioning and biogeochemical processes. The mechanistic representation of these processes allows for the identification of key drivers influencing plankton seasonal succession and uncovers the roles of various functional groups in community interactions such as competition and predation. The incorporation of MARBL-SPECTRA into CESM enables mechanistic projections of how plankton communities are responding to seasonal and interannual changes in their environment as well as how they might respond to future environmental change. The inclusion of more plankton functional types and size classes improves the representation of plankton spatial and temporal biogeography. Highly productive regions tend to be dominated by fast-growing nutrient opportunists (i.e. small diatoms) (Fig. S3). Stratified, unproductive oligotrophic regions are dominated by slow-growing microbes with high nutrient affinity (i.e., picoplankton) (Fig. S3), whose low nutrient requirements tied with their low growth and mortality rates allow them to prevail throughout the year. The largest phytoplankton survive mainly in higher latitudes in large part because their losses to predation are relatively low, even though they tend to grow slowly and are less competitive for nutrients compared with smaller phytoplankton. Additionally, including picoplankton in MARBL-SPECTRA compared to previous versions of CESM was key in differentiating community size structure across the globe. These advantages were particularly apparent in the oligotrophic gyres of the ocean, where pi- 
coplankton contribute to about $70 \%$ of the total Chl, substantially improving the dynamic range of chlorophyll in the model.

The more diverse plankton community in MARBL-SPECTRA simulates the seasonal succession of plankton communities tied to nutrient delivery, temperature, light availability, and grazing pressure. Diatoms dominate the spring bloom in temperate regions due to the onset of thermal stratification increasing light availability. Sufficient light and nutrient supply aid the rapid growth of the smallest diatoms. Mixed phytoplankton develop in late spring following strong microzooplankton and mesozooplankton grazing pressure on diatoms. In autumn, a weaker small diatom bloom occurs in many regions, driven by nutrient delivery to the surface due to enhanced mixing under favorable light conditions. In polar regions, this small diatom bloom is shifted towards boreal and austral summer due to lower light availability and sea ice dynamics influencing phytoplankton growth. The small diatoms and mixed phytoplankton dominate the onset of the bloom, but larger diatoms still contribute to overall biomass due to high nutrient concentrations. This bloom declines with increased microzooplankton and mesozooplankton grazing and decreases in light availability towards the end of the summer. Tropical and subtropical regions display a weaker seasonality in phytoplankton blooms coming from more stable light availability throughout the year and lower nutrient concentrations. Throughout the tropics and subtropics, but especially in oligotrophic regions of the ocean, picoplankton dominate throughout the year, with lower contributions of mixed phytoplankton and diatoms to overall biomass.

The grazing relationships between predator and prey capture information on food chain length and zooplankton trophic level with apparent differences across productive and unproductive regions of the ocean. In low-productivity waters, picoplankton are the dominant phytoplankton type (Fig. $7 \&$ 8), with microzooplankton as their main predators, consuming $75 \%$ of the primary production in oligotrophic regions. The remaining production is channeled directly through mesozooplankton or lost to sinking and other advective processes. The tight coupling between phytoplankton, microzooplankton, and mesozooplankton results in longer food chains in oligotrophic regions composed of more trophic levels (Fig. 10b) compared to other regions in the ocean. Oligotrophic regions in the model favor the recycling of organic matter rather than its efficient transfer upward toward higher trophic levels (Azam et al., 1983; Legendre and Le Fèvre, 1995). Meanwhile, productive regions are characterized by shorter trophic pathways (Fig. 10b) with a larger frac- 
tion of particulate organic carbon exported from the euphotic zone (Fig. S9). This is due either directly through the sinking of ungrazed cells or indirectly through the sedimentation of aggregated detritus and zooplankton fecal pellets, resulting in a biological pump more efficient in transporting biogenic carbon towards the ocean's interior (Guidi et al., 2009; Boyd and Trull, 2007).

The increased model resolution of phytoplankton and zooplankton size classes enables us to study the relative abundance of predators and prey across regions of contrasting productivity. Zooplankton to phytoplankton biomass ratios $(\mathrm{Z}: \mathrm{P})$ are consistent with a $3 / 4$ scaling exponent observed by Hatton et al. (2015), with zooplankton biomass increasing at a lower rate than phytoplankton biomass. Coastal upwelling and other productive regions of the ocean display lower zooplankton to phytoplankton biomass fractions compared with oligotrophic regions of the ocean. The decrease in Z:P ratio with a eutrophication gradient is consistent with observations (Gasol et al., 1997; Yuan and Pollard, 2018; Hatton et al., 2015), but deviates from other modelling analyses that show an increase in in $\mathrm{Z}: \mathrm{P}$ ratio with a eutrophication gradient (Ward et al., 2014; Vallina et al., 2014). One reason for lower Z:P ratios in productive regions could be due to the longer generation times of mesozooplankton (weeks to months) compared to microzooplankton (days), which may impede them from thriving in upwelling regions where strong fluctuations in food supply and environmental conditions occur. Additionally, the use of the Holling Type II grazing function, which keeps predation pressure relatively high at low prey concentrations, may prevent mesozooplankton production from decreasing too much in oligotrophic regions of the ocean. Another reason for this deviation could be due to the high sensitivity of zooplankton biomass to linear and quadratic mortality values in the model. Higher zooplankton quadratic mortalities for the mesozooplankton reflect higher trophic level grazing. The high mortality values can therefore decrease mesozooplankton biomass especially in upwelling regions of the ocean, contributing to a weaker dynamic range in mesozooplankton biomass between oligotrophic and eutrophic regions.

\subsection{Limitations \& future improvement}

All plankton community models, including MARBL-SPECTRA, are simplifications of natural plankton communities that seek to simulate phytoplankton physiology, predator-prey interactions, community structure, and biodiversity in a dynamic environment. MARBL-SPECTRA incorporates 9 
phytoplankton and 6 zooplankton types, where the traits of organisms and their interactions are determined by organism size and functional group, in the case of phytoplankton. While this approach is computationally tractable and allows for the study of lower tropic levels in the marine environment, it has several important limitations.

First, our model does not account for zooplankton life histories such as diapause. Diapause is a critical component of the life history of copepods, as it allows them to survive long periods of unfavorable environmental conditions (Hairston Jr and Munns Jr, 1984). Copepods accumulate lipid reserves prior to diapause, and are highly nutritious prey for a wide variety of predators in the oceans (Bauermeister and Sargent, 1979). Diapausing copepods are especially important in polar, subpolar, and temperate environments where Calanoid copepods are a key intermediary in the process of trophic energy transfer from phytoplankton to higher trophic levels (Baumgartner and Tarrant, 2017). The exclusion of zooplankton life histories can bias mesozooplankton biomass in polar, subpolar, and temperate regions, particularly in the spring (Fig. 9), when copepods are emerging from diapause. As a consequence, there may be insufficient top-down control on the spring phytoplankton bloom, thought to be one of the key mechanisms controlling bloom timing (Banse, 2013).

Second, some key phytoplankton and zooplankton functional groups are absent from the model. Calcifying phytoplankton are a key functional group important in the carbon cycle, producing more than half of the marine carbonate flux (Schiebel, 2002). Although MARBL-SPECTRA accounts for this group implicitly, the inclusion of explicit calcifiers could improve the spatial and temporal representation of calcium carbonate production, as well as incorporate key carbon fertilization mechanisms thought to buffer coccolithophore responses to climate change (Krumhardt et al., 2017, 2019). In addition, phytoplankton dimethyl sulfide (DMS)-producers influence the atmospheric sulfur cycle by producing dimethysulfoniopropionate (DMSP) and convert it into DMS using an extracellular enzyme (DMSP-lyase) (Stefels et al., 1995). Phaeocystisantarctica is especially important in the Southern Ocean, where it has been observed to dominate the community during blooms (Alvain et al., 2008). The high prevalence in Phaeocystis blooms make it an important contributor to primary production and biogeochemical cycles where it occurs. The explicit incorporation of gelatinous zooplankton, such as Cnidarian jellyfish and salps, could improve the representation of top-down control on prey and the representation of carbon transfer effi- 
ciency to depth (Luo et al., 2020). The ability of multiphagous gelatinous zooplankton to feed across a wide spectrum of size classes would provide an indirect route of carbon flux by which even small phytoplankton biomass can be transferred to the deep ocean.

Third, our model does not include zooplankton vertical migration, the active transport of organic carbon to depth by zooplankton consuming organic particles at the surface during the night and respiring the inorganic nutrients below the mixed layer during the day (Steinberg et al., 2000; Longhurst and Harrison, 1988). While the global inventory of carbon export is constrained in models by ocean circulation and the upward flux of nutrients driving new production, zooplankton diel vertical migration could be an important component in mesopelagic zones, contributing significantly to oxygen consumption, particularly at oxygen minimum zones, and carbon export into the ocean interior (Bianchi et al., 2013; Aumont et al., 2018).

Fourth, MARBL-SPECTRA does not represent mixotrophy. Mixotrophs combine the autotrophic use of light and inorganic resources with the heterotrophic ingestion of prey. The incorporation of mixotrophy in ecological models enhances the transfer of biomass to larger organisms at higher trophic levels, which in turn increases the efficiency of oceanic carbon storage through the production of larger, faster-sinking, and carbon-enriched organic detritus (Ward and Follows, 2016). The exclusion of mixotrophy decreases the production of larger phytoplankton, because the nutrient affinity of plankton decreases with increasing organism size 2 . The highly efficient uptake of the small phytoplankton leaves insufficient nutrients to support photosynthesis in the larger groups, especially the mixed phytoplankton group.

Fifth, MARBL-SPECTRA does not include an explicit representation of higher trophic levels (fish, carnivorous jellies, etc.). Zooplankton losses to consumption by higher predators are implicitly modelled using a squared mortality term, which has a tendency to stabilize food webs (Edwards, 2001). Feedbacks between the higher trophic level predator and zooplankton are not resolved. One implication of this simplification is that the ecosystem effects of fishing, for example, cannot be resolved by MARBL-SPECTRA.

Lastly, bacterial activity is not explicitly modeled in our ecosystem model. The effect of the microbial loop is included through constant degradation rates of bacterial remineralization. That is, mortality and exudation losses are recycled to inorganic nutrients via constant rate degradation of several pools of organic matter (dissolved and particulate) for each essential element. Modelling bacterial activity explicitly would increase the model's realism at 
capturing the microbial food web dynamics, but it should not significantly change our results because bacterial abundances are generally more stable than phytoplankton abundances seasonally in open-ocean waters (Spitz et al., 2001).

\subsection{Outlook}

Plankton community models embedded in ocean biogeochemical and circulation models are powerful tools for examining how organism traits shape species biogeography, interactions within plankton communities, the impacts of environmental changes on marine ecosystems, and feedbacks between ecosystems and biogeochemical cycles (e.g., Kwiatkowski et al., 2020; Follows et al., 2007; Ward et al., 2012; Dutkiewicz et al., 2015b). Here, we have developed and evaluated MARBL-SPECTRA, a trait-based plankton community model that resolves nine phytoplankton sizes classes across four functional groups and six zooplankton size classes, allowing for an enhanced understanding of the underlying mechanisms regulating marine plankton biogeography, and the community's role in biogeochemical cycles. Future increases in ocean temperatures and other environmental properties are expected to modify phytoplankton community diversity and distribution through a range of direct and indirect pathways and mechanisms, many of which are simulated in MARBL-SPECTRA. The future incorporation of MARBL-SPECTRA in a fully coupled climate model would allow for the projection of model organism fitness into the future to better predict changes in plankton communities structure, biogeochemical cycles, food web dynamics, and air-sea fluxes of climate-active gases.

\section{Acknowledgements}

We acknowledge high-performance computing support from Cheyenne (doi:10.5065/D6RX99HX) provided by NCAR's Computational and Information Systems Laboratory, sponsored by the National Science Foundation (NSF). This manuscript is based upon work supported by the National Center for Atmospheric Research, which is a major facility sponsored by the National Science Foundation under Cooperative Agreement No. 1852977, and the National Science Foundation Graduate Research Fellowship under Grant No. (DGE-2038238 and DGE-1650112). Any opinions, findings, and conclusions or recommendations expressed in this material are those of the author(s) and do not necessarily reflect the views of the National Science 


\section{Supplementary Information}

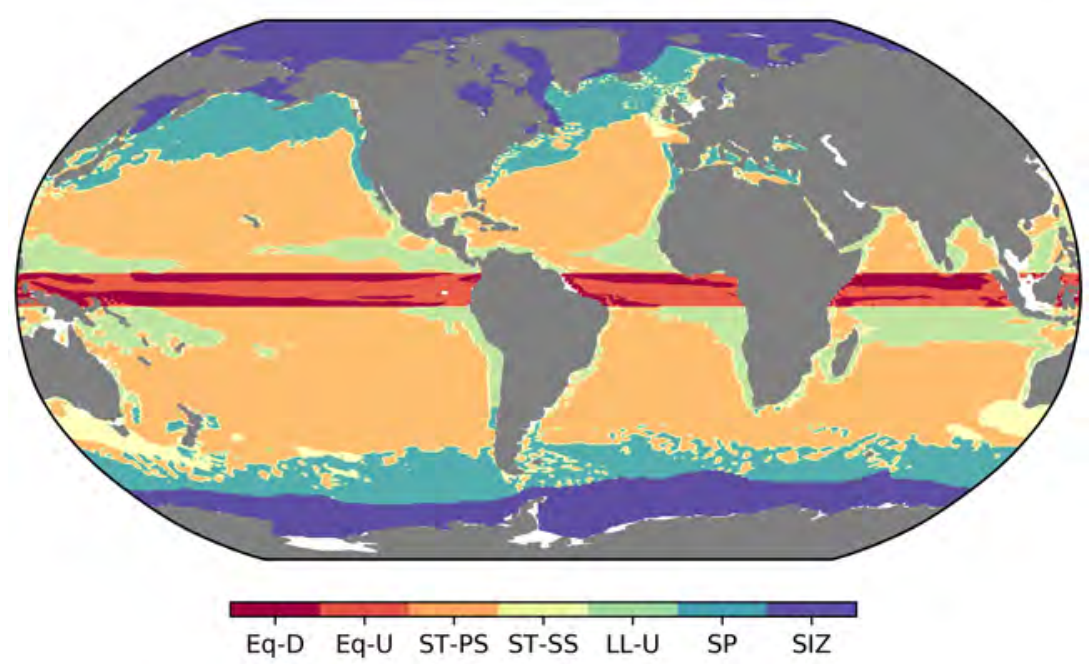

Figure S1: Biomes. Designated oceanic biomes, using Sarmiento et al. (2004): Equatorial downwelling (Eq-D), Equatorial upwelling (Eq-U), Subtropical permanently stratified (STPS), Subtropical seasonally stratified (ST-SS), Lower latitude upwelling (LL-U), Sub-polar seasonally stratified (SP), Seasonal ice-covered zone (SIZ). In the analyses, the northern and Southern Hemisphere biomes are separated 


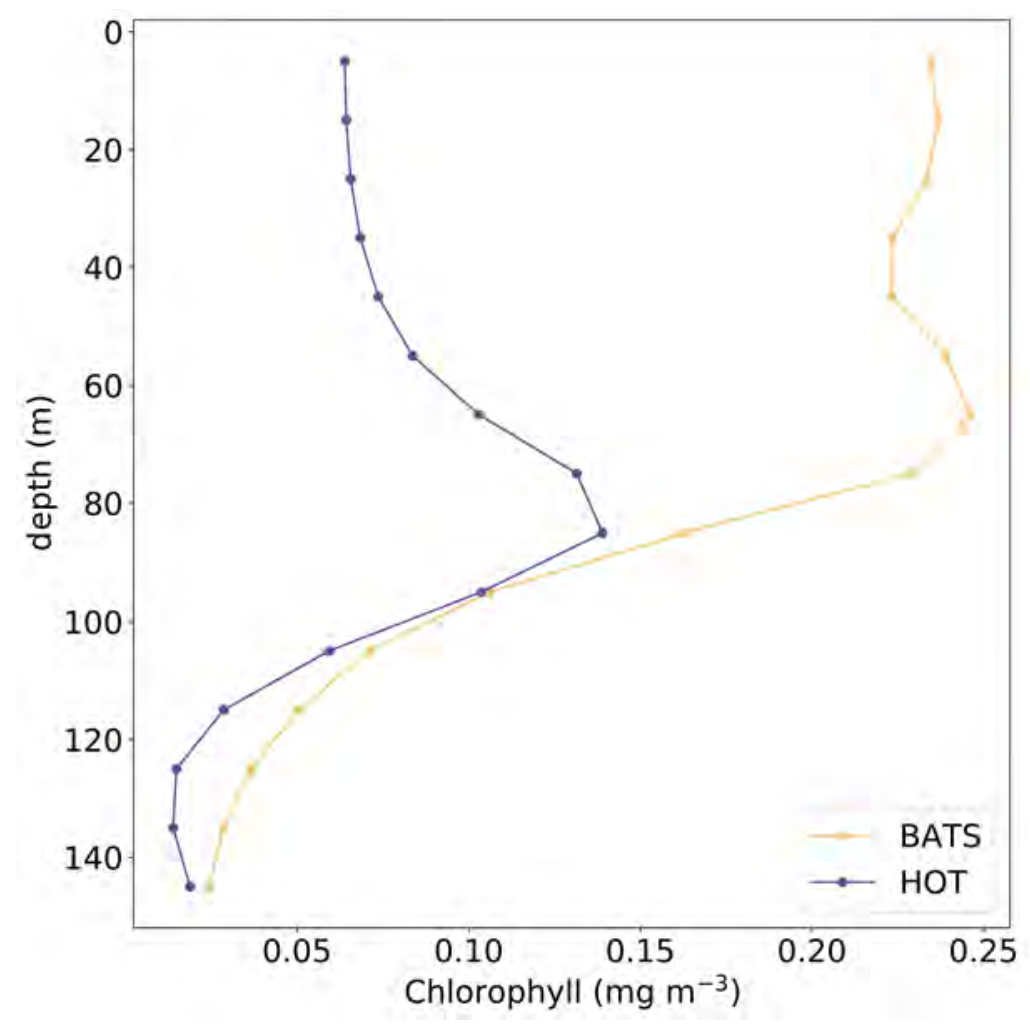

Figure S2: Modelled annual average chlorophyll $\left(\mathrm{mg} \mathrm{m}^{-3}\right)$ vertical profiles in the (a) BATS, and (b) HOT station over the period 1990 and 2009. 

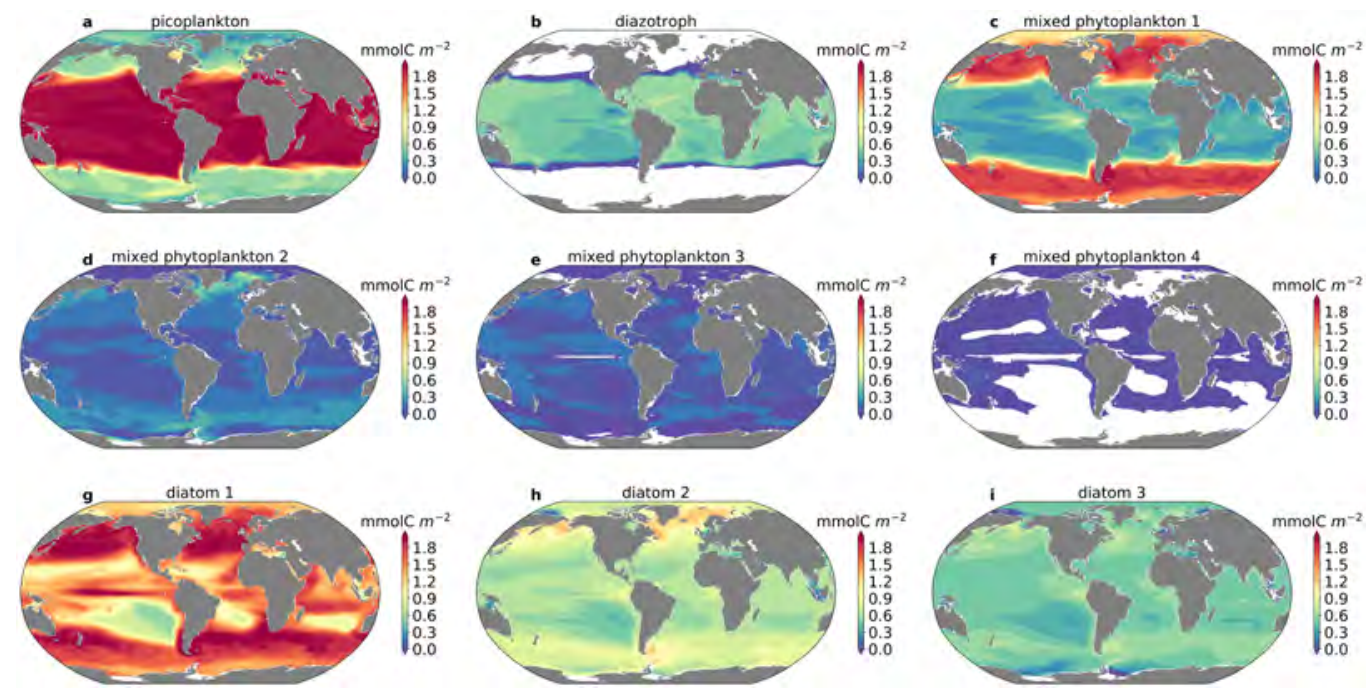

Figure S3: Phytoplankton biomass. Depth integrated average annual phytoplankton biomass for each phytoplankton type: (a) picoplankton (b) diazotrophs, (c) smallest mixed phytoplankton, (d) second smallest mixed phytoplankton, (e) second largest mixed phytoplankton, (f) largest mixed phytoplankton, (g) smallest diatom, (h) medium diatom and (i) largest diatom.
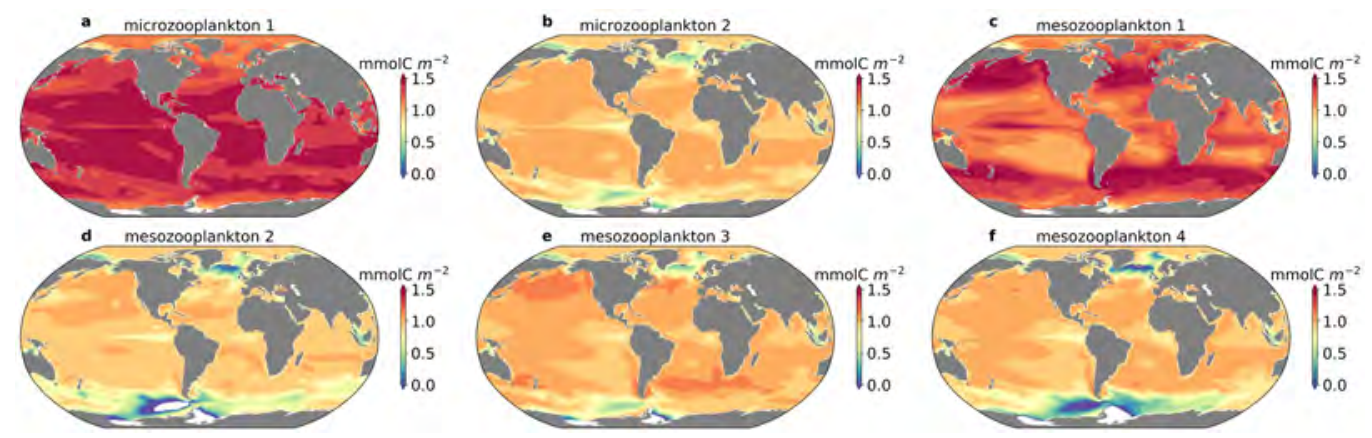

Figure S4: Zooplankton biomass. Depth integrated average annual zooplankton biomass for each zooplankton type: (a) smallest microzooplankton (microzooplankton 1) (b) largest microzooplankton (microzooplankton 2), (c) smallest mesozooplankton (mesozooplankton 1), (d) second smallest mesozooplankton (mesozooplankton 2), (e) medium mesozooplankton (mesozooplankton 3), and (f) largest mesozooplankton (mesozooplankton 4). 

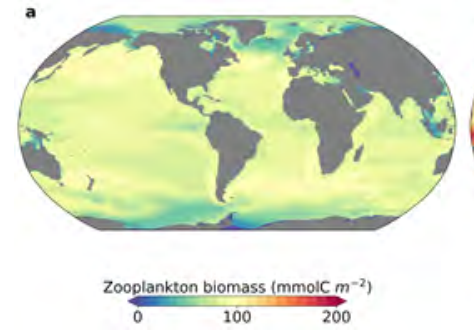

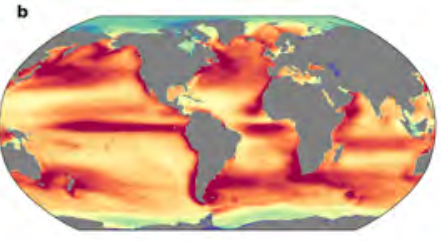

Phytoplankton biomass (mmolc m $^{-2}$ )

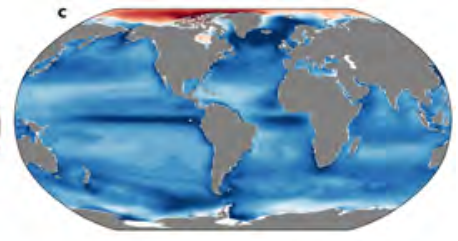

Zooplankton / Phytoplankton biomass ratio

Figure S5: Depth integrated carbon biomass over 1990-2009 for (a) zooplankton (mmol $\mathrm{C} \mathrm{m}^{-2}$ ) and (a) phytoplankton $\left(\mathrm{mmol} \mathrm{C} \mathrm{m}^{-2}\right)$; (c) shows the ratio of depth-integrated zooplankton to phytoplankton biomass over 1990-2009.
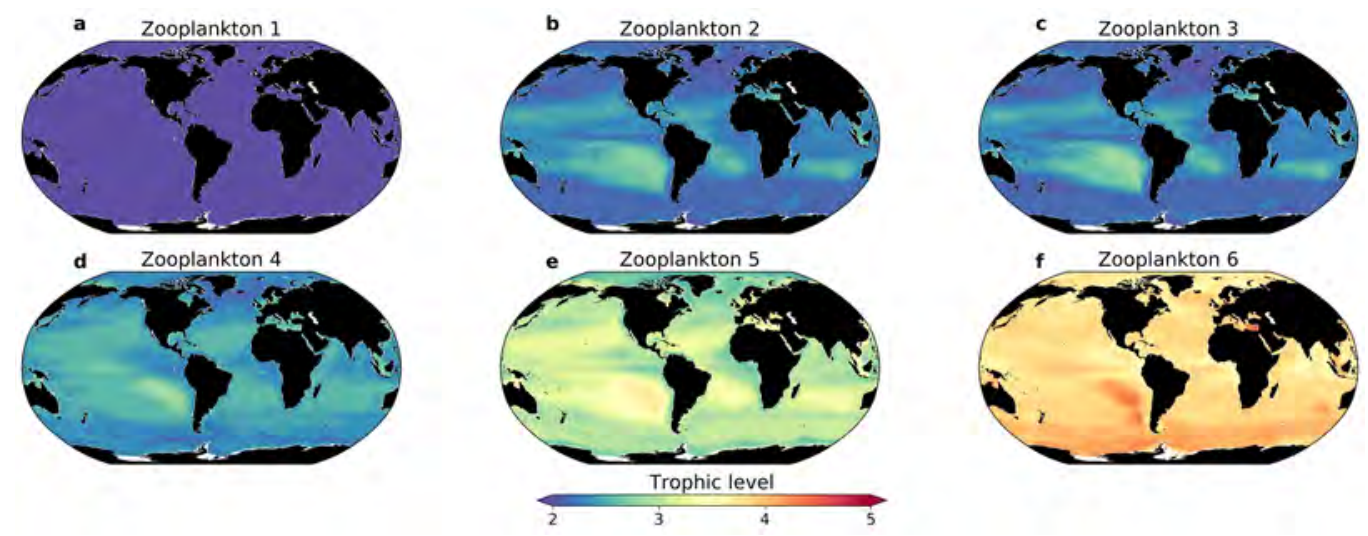

Figure S6: Zooplankton annual mean trophic level over the top $150 \mathrm{~m}$ between 1990 and 2009. (a) smallest microzooplankton (microzooplankton 1) (b) largest microzooplankton (microzooplankton 2), (c) smallest mesozooplankton (mesozooplankton 1), (d) second smallest mesozooplankton (mesozooplankton 2), (e) medium mesozooplankton (mesozooplankton 3), and (f) largest mesozooplankton (mesozooplankton 4). 

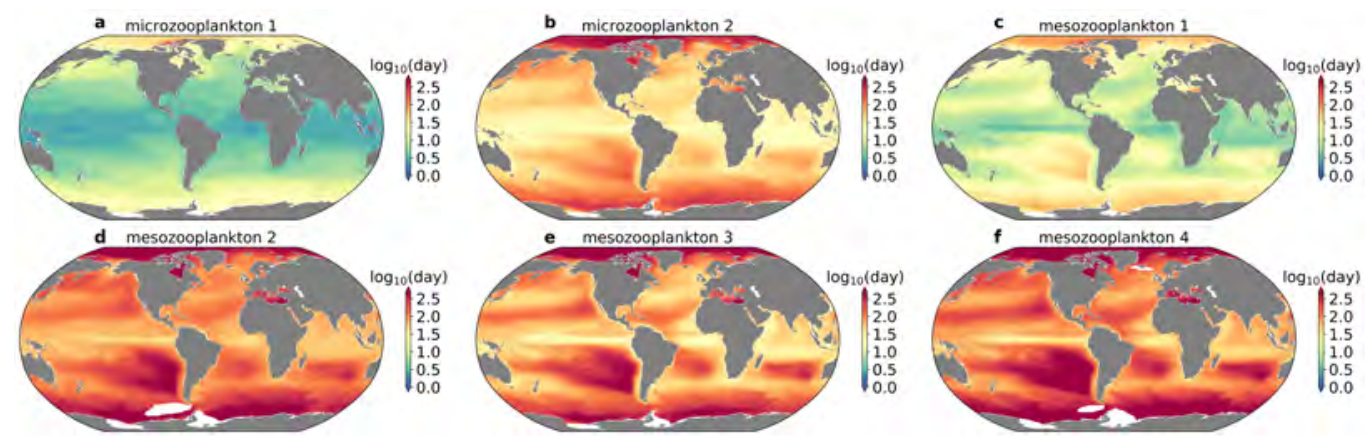

Figure S7: Zooplankton generation time. The average annual generation time is the zooplankton biomass divided by the zooplankton production at the top $150 \mathrm{~m}$ for each zooplankton type: (a) smallest microzooplankton (microzooplankton 1) (b) largest microzooplankton (microzooplankton 2), (c) smallest mesozooplankton (mesozooplankton 1), (d) second smallest mesozooplankton (mesozooplankton 2), (e) medium mesozooplankton (mesozooplankton 3), and (f) largest mesozooplankton (mesozooplankton 4).
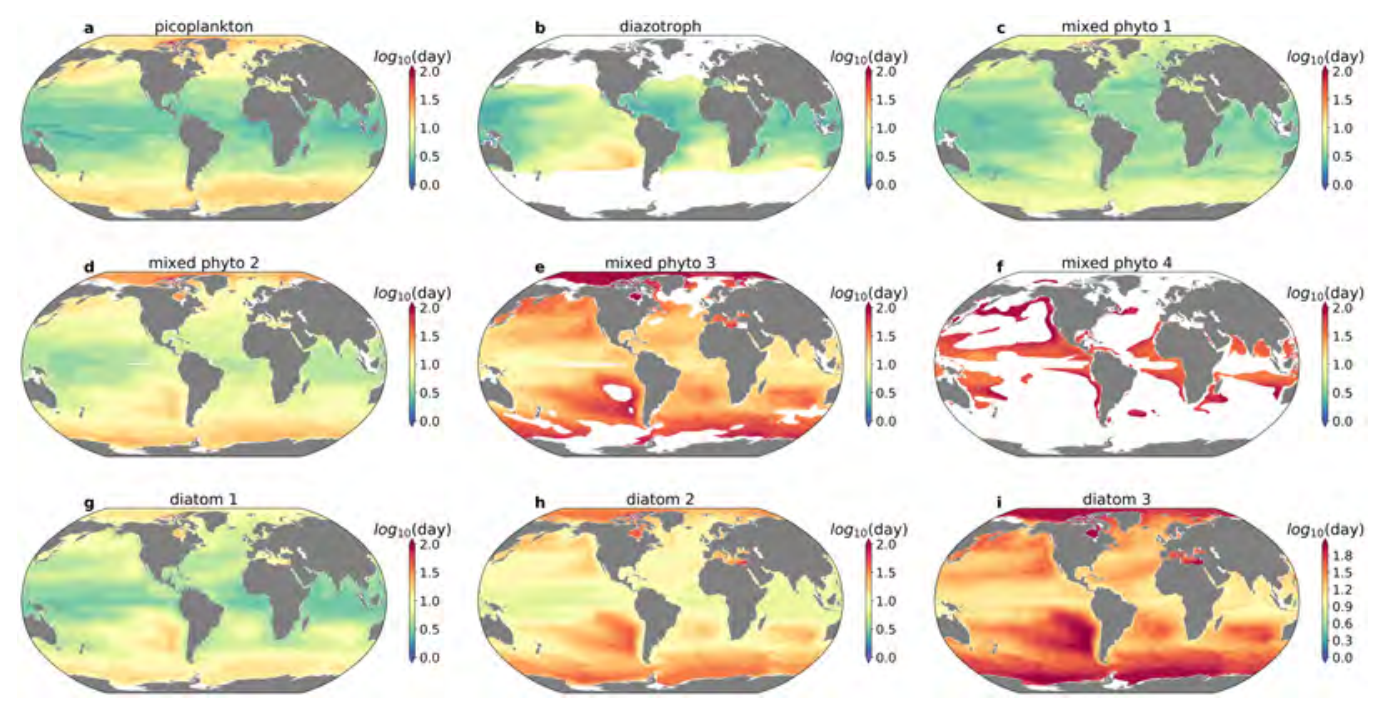

Figure S8: Phytoplankton generation time. The average annual generation time represents the phytoplankton biomass divided by the phytoplankton production at the top 150m for each phytoplankton type: (a) picoplankton (b) diazotrophs, (c) smallest mixed phytoplankton, (d) second smallest mixed phytoplankton, (e) second largest mixed phytoplankton, (f) largest mixed phytoplankton, (g) smallest diatom, (h) medium diatom and (i) largest diatom. 
bioRxiv preprint doi: https://doi.org/10.1101/2022.02.01.478546; this version posted February 1, 2022. The copyright holder for this preprint (which was not certified by peer review) is the author/funder, who has granted bioRxiv a license to display the preprint in perpetuity. It is made available under aCC-BY-NC-ND 4.0 International license.
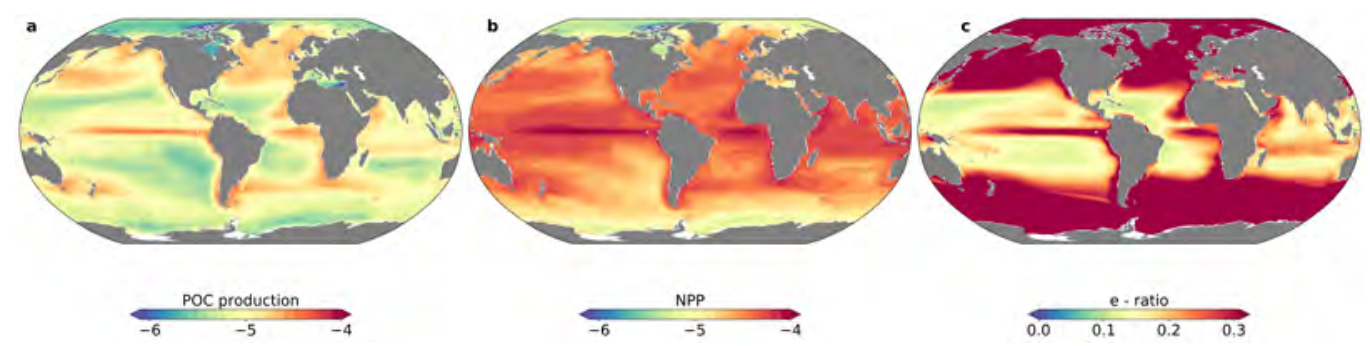

Figure S9: Annual mean $\log _{10}$ POC production (a), annual mean $\log _{10}$ NPP (b), and export ratio (e-ratio) (c) at the top 150m between 1990 and 2009. 


\section{References}

Acevedo-Trejos, E., Brandt, G., Bruggeman, J., Merico, A., 2015. Mechanisms shaping size structure and functional diversity of phytoplankton communities in the ocean. Scientific reports $5,1-8$.

Aksnes, D.L., Egge, J.K., 1991. A theoretical model for nutrient uptake in phytoplankton. Marine ecology progress series. Oldendorf 70, 65-72.

Allen, A.P., Gillooly, J.F., Brown, J.H., 2005. Linking the global carbon cycle to individual metabolism. Functional Ecology 19, 202-213.

Aloisi, G., 2015. Covariation of metabolic rates and cell size in coccolithophores. Biogeosciences 12, 4665-4692. doi:10.5194/bg-12-4665-2015.

Alvain, S., Moulin, C., Dandonneau, Y., Loisel, H., 2008. Seasonal distribution and succession of dominant phytoplankton groups in the global ocean: A satellite view. Global Biogeochemical Cycles 22.

Anderson, L.A., Sarmiento, J.L., 1994. Redfield ratios of remineralization determined by nutrient data analysis. Global biogeochemical cycles 8, 6580 .

Anderson, S., Barton, A., Clayton, S., Dutkiewicz, S., Rynearson, T., 2021. Marine phytoplankton functional types exhibit diverse responses to thermal change. Nature communications 12, 1-9.

Armstrong, R.A., Lee, C., Hedges, J.I., Honjo, S., Wakeham, S.G., 2002. A new, mechanistic model for organic carbon fluxes in the ocean based on the quantitative association of poc with ballast minerals. Deep-Sea Research II 49, 219-236.

Arrhenius, S., 1915. Quantitative laws in biological chemistry. volume 1915. G. Bell.

Aumont, O., Éthé, C., Tagliabue, A., Bopp, L., Gehlen, M., 2015. Piscesv2: an ocean biogeochemical model for carbon and ecosystem studies. Geoscientific Model Development 8, 2465-2513.

Aumont, O., Maier-Reimer, E., Blain, S., Monfray, P., 2003. An ecosystem model of the global ocean including fe, si, p colimitations. Global Biogeochemical Cycles 17. 
Aumont, O., Maury, O., Lefort, S., Bopp, L., 2018. Evaluating the potential impacts of the diurnal vertical migration by marine organisms on marine biogeochemistry. Global Biogeochemical Cycles 32, 1622-1643.

Azam, F., Fenchel, T., Field, J.G., Gray, J., Meyer-Reil, L., Thingstad, F., 1983. The ecological role of water-column microbes in the sea. Marine ecology progress series , 257-263.

Banas, N.S., 2011. Adding complex trophic interactions to a size-spectral plankton model: Emergent diversity patterns and limits on predictability. Ecological Modelling 222, 2663-2675. doi:10.1016/j.ecolmodel.2011.05.018.

Banse, K., 2013. Reflections about chance in my career, and on the top-down regulated world. Annual Review of Marine Science 5, 1-19.

Barnes, C., Bethea, D., Brodeur, R., Spitz, J., Ridoux, V., Pusineri, C., Chase, B., Hunsicker, M., Juanes, F., Kellermann, A., et al., 2008. Predator and prey body sizes in marine food webs: Ecological archives e089-051. Ecology 89, 881-881.

Barton, A.D., Dutkiewicz, S., Flierl, G., Bragg, J., Follows, M.J., 2010. Patterns of diversity in marine phytoplankton. Science 327, 1509-1511.

Barton, A.D., Pershing, A.J., Litchman, E., Record, N.R., Edwards, K.F., Finkel, Z.V., Kiørboe, T., Ward, B.A., 2013. The biogeography of marine plankton traits. Ecology letters 16, 522-534.

Bauermeister, A., Sargent, J., 1979. Wax esters: major metabolites in the marine environment. Trends in Biochemical Sciences 4, 209-211.

Baumgartner, M.F., Tarrant, A.M., 2017. The physiology and ecology of diapause in marine copepods. Annual Review of Marine Science 9, 387411.

Behrenfeld, M.J., 2014. Climate-mediated dance of the plankton. Nature Climate Change 4, 880-887.

Behrenfeld, M.J., Boss, E., 2003. The beam attenuation to chlorophyll ratio: an optical index of phytoplankton physiology in the surface ocean? Deep Sea Research Part I: Oceanographic Research Papers 50, 1537-1549. 
Behrenfeld, M.J., Boss, E., Siegel, D.A., Shea, D.M., 2005. Carbon-based ocean productivity and phytoplankton physiology from space. Global Biogeochemical Cycles 19, 1-14. doi:10.1029/2004GB002299.

Behrenfeld, M.J., Marañón, E., Siegel, D.A., Hooker, S.B., 2002. Photoacclimation and nutrient-based model of light-saturated photosynthesis for quantifying oceanic primary production. Marine Ecology Progress Series 228, 103-117.

Bertilsson, S., Berglund, O., Karl, D.M., Chisholm, S.W., 2003. Elemental composition of marine prochlorococcus and synechococcus: Implications for the ecological stoichiometry of the sea. Limnol. Oceanogr 48, 17211731.

Beusen, A., Van Beek, L., Bouwman, A., Mogollón, J., Middelburg, J., 2015. Coupling global models for hydrology and nutrient loading to simulate nitrogen and phosphorus retention in surface water-description of imagegnm and analysis of performance. Geoscientific model development 8, 4045-4067.

Beusen, A.H., Bouwman, A.F., Van Beek, L.P., Mogollón, J.M., Middelburg, J.J., 2016. Global riverine $\mathrm{n}$ and $\mathrm{p}$ transport to ocean increased during the 20th century despite increased retention along the aquatic continuum. Biogeosciences 13, 2441-2451.

Bianchi, D., Galbraith, E.D., Carozza, D.A., Mislan, K., Stock, C.A., 2013. Intensification of open-ocean oxygen depletion by vertically migrating animals. Nature Geoscience 6, 545-548.

Boyd, P., Trull, T., 2007. Understanding the export of biogenic particles in oceanic waters: Is there consensus? Progress in Oceanography 72, $276-312$.

Boyd, P.W., Strzepek, R., Fu, F., Hutchins, D.A., 2010. Environmental control of open-ocean phytoplankton groups: Now and in the future. Limnology and Oceanography 55, 1353-1376.

Breitbarth, E., Wohlers, J., Kläs, J., LaRoche, J., Peeken, I., 2008. Nitrogen fixation and growth rates of trichodesmium ims-101 as a function of light intensity. Marine Ecology Progress Series 359, 25-36. 
Bruggeman, J., Kooijman, S.A., 2007. A biodiversity-inspired approach to aquatic ecosystem modeling. Limnology and Oceanography 52, 1533-1544.

Carlotti, F., Giske, J., Werner, F., 2000. Modeling zooplankton dynamics, in: ICES zooplankton methodology manual. Elsevier, pp. 571-667.

Carr, M.E., Friedrichs, M.A., Schmeltz, M., Aita, M.N., Antoine, D., Arrigo, K.R., Asanuma, I., Aumont, O., Barber, R., Behrenfeld, M., Bidigare, R., Buitenhuis, E.T., Campbell, J., Ciotti, A., Dierssen, H., Dowell, M., Dunne, J., Esaias, W., Gentili, B., Gregg, W., Groom, S., Hoepffner, N., Ishizaka, J., Kameda, T., Quéré, C.L., Lohrenz, S., Marra, J., Mélin, F., Moore, K., Morel, A., Reddy, T.E., Ryan, J., Scardi, M., Smyth, T., Turpie, K., Tilstone, G., Waters, K., Yamanaka, Y., 2006. A comparison of global estimates of marine primary production from ocean color. Deep-Sea Research Part II: Topical Studies in Oceanography 53, 741-770. doi:10.1016/j.dsr2.2006.01.028.

Cermeño, P., Marañón, E., Harbour, D., Harris, R.P., 2006. Invariant scaling of phytoplankton abundance and cell size in contrasting marine environments. Ecology letters 9, 1210-1215.

Chen, B., Liu, H., Huang, B., Wang, J., 2014. Temperature effects on the growth rate of marine picoplankton. Marine Ecology Progress Series 505, 37-47. doi:10.3354/meps10773.

Chisholm, S.W., 1992. Phytoplankton size.

Cohen, J.E., Pimm, S.L., Yodzis, P., Saldaña, J., 1993. Body sizes of animal predators and animal prey in food webs. Journal of animal ecology , 67-78.

Conley, K.R., Lombard, F., Sutherland, K.R., 2018. Mammoth grazers on the ocean's minuteness: a review of selective feeding using mucous meshes. Proceedings of the Royal Society B: Biological Sciences 285, 20180056.

Cullen, J.J., MacIntyre, J.G., 1998. Behavior, physiology and the niche of depth-regulating phytoplankton. Nato Asi Series G Ecological Sciences 41, 559-580.

Danabasoglu, G., Bates, S.C., Briegleb, B.P., Jayne, S.R., Jochum, M., Large, W.G., Peacock, S., Yeager, S.G., 2012. The ccsm4 ocean component. Journal of Climate 25, 1361-1389. 
DeVries, T., Weber, T., 2017. The export and fate of organic matter in the ocean: New constraints from combining satellite and oceanographic tracer observations. Global Biogeochemical Cycles 31, 535-555.

Dunne, J.P., Sarmiento, J.L., Gnanadesikan, A., 2007. A synthesis of global particle export from the surface ocean and cycling through the ocean interior and on the seafloor. Global Biogeochemical Cycles 21. doi:10.1029/2006GB002907.

Dutkiewicz, S., Cermeno, P., Jahn, O., Follows, M., Hickman, A., Taniguchi, D., Ward, B., 2019. Dimensions of marine phytoplankton diversity. Biogeosciences Discussions , 1-46doi:10.5194/bg-2019-311.

Dutkiewicz, S., Hickman, A.E., Jahn, O., Gregg, W.W., Mouw, C.B., Follows, M.J., 2015a. Capturing optically important constituents and properties in a marine biogeochemical and ecosystem model. Biogeosciences 12, 4447-4481. doi:10.5194/bg-12-4447-2015.

Dutkiewicz, S., Morris, J.J., Follows, M.J., Scott, J., Levitan, O., Dyhrman, S.T., Berman-Frank, I., 2015b. Impact of ocean acidification on the structure of future phytoplankton communities. Nature Climate Change 5, 1002-1006. doi:10.1038/nclimate2722.

Edwards, A.M., 2001. Adding detritus to a nutrient-phytoplanktonzooplankton model: a dynamical-systems approach. Journal of Plankton Research 23, 389-413.

Edwards, K.F., Klausmeier, C.A., Litchman, E., 2015a. Nutrient utilization traits of phytoplankton ecological archives e096-202. Data Papers Ecology 96, 2311. URL: http://esapubs.org/archive.

Edwards, K.F., Thomas, M.K., Klausmeier, C.A., Litchman, E., 2012. Allometric scaling and taxonomic variation in nutrient utilization traits and maximum growth rate of phytoplankton. Limnology and Oceanography 57, 554-566. doi:10.4319/lo.2012.57.2.0554.

Edwards, K.F., Thomas, M.K., Klausmeier, C.A., Litchman, E., 2015b. Light and growth in marine phytoplankton: Allometric, taxonomic, and environmental variation. Limnology and Oceanography 60, 540-552. doi:doi: 10.1002/lno.10033. 
Eppley, R.W., 1972. Temperature and phytoplankton growth in the sea. Fish. bull 70, 1063-1085.

Eppley, R.W., Rogers, J.N., McCarthy, J.J., 1969. Half-saturation constants for uptake of nitrate adn ammonium by marine phytoplankton. Limnology and oceanography 14, 912-920.

Evans, G.T., Parslow, J.S., 1985. A model of annual plankton cycles. Biological oceanography 3, 327-347.

Falcón, L.I., Pluvinage, S., Carpenter, E.J., 2005. Growth kinetics of marine unicellular n2-fixing cyanobacterial isolates in continuous culture in relation to phosphorus and temperature. Marine Ecology Progress Series 285, 3-9.

Falkowski, P.G., Dubinsky, Z., Wyman, K., 1985. Growth-irradiance re.lationships in phytoplankton'. Limnol. Oceanogr 30, 311-321.

Fasham, M.J., Ducklow, H.W., McKelvie, S.M., 1990. A nitrogen-based model of plankton dynamics in the oceanic mixed layer. Journal of Marine Research 48, 591-639.

Field, C.B., Behrenfeld, M.J., Randerson, J.T., Falkowski, P., 1998. Primary production of the biosphere: integrating terrestrial and oceanic components. science 281, 237-240.

Finkel, Z.V., 2001. Light absorption and size scaling of light-limited metabolism in marine diatoms. Limnology and oceanography 46, 86-94.

Finkel, Z.V., Beardall, J., Flynn, K.J., Quigg, A., Rees, T.A.V., Raven, J.A., 2010. Phytoplankton in a changing world: Cell size and elemental stoichiometry. Journal of Plankton Research 32, 119-137. doi:10.1093/plankt/fbp098.

Follows, M.J., Dutkiewicz, S., Grant, S., Chisholm, S.W., 2007. Emergent biogeography of microbial communities in a model ocean. Science 315, 1843-1846. doi:10.1126/science.1138544.

Franks, P.J., 2002. Npz models of plankton dynamics: their construction, coupling to physics, and application. Journal of Oceanography 58, 379387. 
Fu, F.X., Zhang, Y., Bell, P.R., Hutchins, D.A., 2005. Phosphate uptake and growth kinetics of trichodesmium (cyanobacteria) isolates from the north atlantic ocean and the great barrier reef, australia 1. Journal of Phycology $41,62-73$.

Fuchs, H.L., Franks, P.J., 2010. Plankton community properties determined by nutrients and size-selective feeding. Marine Ecology Progress Series 413, 1-15. doi:10.3354/meps08716.

Galbraith, E.D., Martiny, A.C., 2015. A simple nutrient-dependence mechanism for predicting the stoichiometry of marine ecosystems. Proceedings of the National Academy of Sciences of the United States of America 112, 8199-8204. doi:10.1073/pnas.1423917112.

Garcia, H., Boyer, T., Baranova, O., Locarnini, R., Mishonov, A., Grodsky, A., Paver, C., Weathers, K., Smolyar, I., Reagan, J., et al., 2019. World ocean atlas 2018: Product documentation. A. Mishonov, Technical Editor

Gasol, J.M., Del Giorgio, P.A., Duarte, C.M., 1997. Biomass distribution in marine planktonic communities. Limnology and Oceanography 42, 13531363.

Geider, R.J., MacIntyre, H.L., Kana, T.M., 1997. Dynamic model of phytoplankton growth and acclimation: responses of the balanced growth rate and the chlorophyll a: carbon ratio to light, nutrient-limitation and temperature. Marine Ecology Progress Series 148, 187-200.

Geider, R.J., Maclntyre, H.L., Kana, T.M., 1998. A dynamic regulatory model of phytoplanktonic acclimation to light, nutrients, and temperature. Limnology and Oceanography 43, 679-694. URL: https://aslopubs.onlinelibrary.wiley.com/doi/abs/10.4319/1o.1998.43.4.0679, doi:https://doi.org/10.4319/lo.1998.43.4.0679.

Geider, R.J., Osbonie, B.A., Raven, J.A., 1986. Growth, photosynthesis and maintenance metabolic cost in the diatom phaeodactylum tricornutum at very low light levels 1 . Journal of Phycology 22, 39-48.

Gent, P.R., Danabasoglu, G., Donner, L.J., Holland, M.M., Hunke, E.C., Jayne, S.R., Lawrence, D.M., Neale, R.B., Rasch, P.J., Vertenstein, M., 
2011. The community climate system model version 4. Journal of climate 24, 4973-4991.

Gillooly, J.F., 2000. Effect of body size and temperature on generation time in zooplankton. Journal of plankton research 22, 241-251.

Gillooly, J.F., Brown, J.H., West, G.B., Savage, V.M., Charnov, E.L., 2001. Effects of size and temperature on metabolic rate. science 293, 2248-2251.

Gillooly, J.F., Charnov, E.L., West, G.B., Savage, V.M., Brown, J.H., 2002. Effects of size and temperature on developmental time. Nature 417, 70-73.

Griffies, S.M., Biastoch, A., Böning, C., Bryan, F., Danabasoglu, G., Chassignet, E.P., England, M.H., Gerdes, R., Haak, H., Hallberg, R.W., et al., 2009. Coordinated ocean-ice reference experiments (cores). Ocean modelling 26, 1-46.

Großkopf, T., Mohr, W., Baustian, T., Schunck, H., Gill, D., Kuypers, M.M.M., Lavik, G., Schmitz, R.A., Wallace, D.W.R., LaRoche, J., 2012. Doubling of marine dinitrogen-fixation rates based on direct measurements. Nature 488, 361-364. URL: https://doi.org/10.1038/nature11338, doi:10.1038/nature11338.

Guidi, L., Stemmann, L., Jackson, G.A., Ibanez, F., Claustre, H., Legendre, L., Picheral, M., Gorskya, G., 2009. Effects of phytoplankton community on production, size, and export of large aggregates: A world-ocean analysis. Limnology and Oceanography 54, 1951-1963.

Hairston Jr, N.G., Munns Jr, W.R., 1984. The timing of copepod diapause as an evolutionarily stable strategy. The American Naturalist 123, 733-751.

Hansen, B., Bjornsen, P.K., Hansen, P.J., 1994. The size ratio between planktonic predators and their prey. Limnology and Oceanography 39, 395-403. doi:10.4319/lo.1994.39.2.0395.

Hansen, P.J., Bjørnsen, P.K., Hansen, B.W., 1997. Zooplankton grazing and growth: Scaling within the $2-2,-\mu \mathrm{m}$ body size range. Limnology and oceanography $42,687-704$.

Hartmann, M., Gomez-Pereira, P., Grob, C., Ostrowski, M., Scanlan, D.J., Zubkov, M.V., 2014. Efficient co2 fixation by surface prochlorococcus in the atlantic ocean. ISME Journal 8, 2280-2289. doi:10.1038/ismej.2014.56. 
Hatton, I.A., McCann, K.S., Fryxell, J.M., Davies, T.J., Smerlak, M., Sinclair, A.R., Loreau, M., 2015. The predator-prey power law: Biomass scaling across terrestrial and aquatic biomes. Science 349.

Heneghan, R.F., Everett, J.D., Sykes, P., Batten, S.D., Edwards, M., Takahashi, K., Suthers, I.M., Blanchard, J.L., Richardson, A.J., 2020. A functional size-spectrum model of the global marine ecosystem that resolves zooplankton composition. Ecological Modelling 435, 109265.

Henson, S.A., Sanders, R., Madsen, E., 2012. Global patterns in efficiency of particulate organic carbon export and transfer to the deep ocean. Global Biogeochemical Cycles 26.

Hirata, T., Hardman-Mountford, N., Brewin, R., Aiken, J., Barlow, R., Suzuki, K., Isada, T., Howell, E., Hashioka, T., Noguchi-Aita, M., et al., 2011. Synoptic relationships between surface chlorophyll-a and diagnostic pigments specific to phytoplankton functional types. Biogeosciences 8, $311-327$.

Hirche, H.J., 1997. Life cycle of the copepod calanus hyperboreus in the greenland sea. Marine Biology 128, 607-618.

Huete-Ortega, M., Cermeno, P., Calvo-Díaz, A., Maranon, E., 2012. Isometric size-scaling of metabolic rate and the size abundance distribution of phytoplankton. Proceedings of the Royal Society B: Biological Sciences 279, 1815-1823.

Hunke, E., Lipscomb, W., Jones, P., Turner, A., Jeffery, N., Elliott, S., 2017. Cice, the los alamos sea ice model, version 00. URL: https://www.osti.gov/biblio/1364126.

Irigoien, X., Huisman, J., Harris, R.P., 2004. Global biodiversity patterns of marine phytoplankton and zooplankton. Nature 429, 863-867.

Johnson, Z.I., Zinser, E.R., Coe, A., McNulty, N.P., Woodward, E.M.S., Chisholm, S.W., 2006. Niche partitioning among prochlorococcus ecotypes along ocean-scale environmental gradients. Science 311, 1737-1740.

Kiørboe, T., 1993. Turbulence, phytoplankton cell size, and the structure of pelagic food webs. Advances in marine biology 29, 1-72. 
Kiørboe, T., 2011. How zooplankton feed: mechanisms, traits and trade-offs. Biological reviews 86, 311-339.

Kirk, J., 1976. A theoretical analysis of the contribution of algal cells to the attenuation of light within natural waters: Iii. cylindrical and spheroidal cells. New Phytologist 77, 341-358.

Kirk, J.T., 1994. Light and photosynthesis in aquatic ecosystems. Cambridge university press.

Kiørboe, T., Hirst, A.G., 2014. Shifts in mass scaling of respiration, feeding, and growth rates across life-form transitions in marine pelagic organisms. American Naturalist 183. doi:10.1086/675241.

Kremer, C.T., Thomas, M.K., Litchman, E., 2017. Temperature- and sizescaling of phytoplankton population growth rates: Reconciling the eppley curve and the metabolic theory of ecology. Limnology and Oceanography 62, 1658-1670. doi:10.1002/lno.10523.

Krumhardt, K.M., Lovenduski, N.S., Iglesias-Rodriguez, M.D., Kleypas, J.A., 2017. Coccolithophore growth and calcification in a changing ocean. Progress in oceanography 159, 276-295.

Krumhardt, K.M., Lovenduski, N.S., Long, M.C., Levy, M., Lindsay, K., Moore, J.K., Nissen, C., 2019. Coccolithophore growth and calcification in an acidified ocean: Insights from community earth system model simulations. Journal of Advances in Modeling Earth Systems 11, 1418-1437.

Kwiatkowski, L., Torres, O., Bopp, L., Aumont, O., Chamberlain, M., Christian, J.R., Dunne, J.P., Gehlen, M., Ilyina, T., John, J.G., et al., 2020. Twenty-first century ocean warming, acidification, deoxygenation, and upper-ocean nutrient and primary production decline from cmip6 model projections. Biogeosciences 17, 3439-3470.

Landry, M.R., Al-Mutairi, H., Selph, K.E., Christensen, S., Nunnery, S., 2001. Seasonal patterns of mesozooplankton abundance and biomass at station aloha. Deep Sea Research Part II: Topical Studies in Oceanography 48, 2037-2061.

Landry, M.R., Calbet, A., 2004. Microzooplankton production in the oceans. ICES Journal of Marine Science 61, 501-507. 
Large, W.G., Yeager, S.G., 2009. The global climatology of an interannually varying air - sea flux data set. Climate Dynamics 33, 341-364. doi:10.1007/s00382-008-0441-3.

Law, R., Plank, M.J., James, A., Blanchard, J.L., 2009. Size-spectra dynamics from stochastic predation and growth of individuals. Ecology 90, 802-811.

Legendre, L., Le Fèvre, J., 1995. Microbial food webs and the export of biogenic carbon in oceans. Aquatic Microbial Ecology 9, 69-77.

Legendre, L., Rassoulzadegan, F., 1996. Food-web mediated export of biogenic carbon in oceans: hydrodynamic control. Marine Ecology Progress Series 145, 179-193.

Letelier, R.M., Karl, D.M., 1998. Trichodesmium spp. physiology and nutrient fluxes in the north pacific subtropical gyre. Aquatic Microbial Ecology $15,265-276$.

Letelier, R.M., Karl, D.M., Abbott, M.R., Bidigare, R.R., 2004. Light driven seasonal patterns of chlorophyll and nitrate in the lower euphotic zone of the north pacific subtropical gyre. Limnology and Oceanography 49, 508519 .

Letscher, R.T., Moore, J.K., 2015. Preferential remineralization of dissolved organic phosphorus and non-redfield dom dynamics in the global ocean: Impacts on marine productivity, nitrogen fixation, and carbon export. Global Biogeochemical Cycles 29, 325-340.

Letscher, R.T., Moore, J.K., Teng, Y.C., Primeau, F., 2015. Variable c: N: P stoichiometry of dissolved organic matter cycling in the community earth system model. Biogeosciences 12, 209-221.

Li, Q.P., Franks, P.J., Landry, M.R., Goericke, R., Taylor, A.G., 2010. Modeling phytoplankton growth rates and chlorophyll to carbon ratios in california coastal and pelagic ecosystems. Journal of Geophysical Research: Biogeosciences 115. doi:10.1029/2009JG001111.

Litchman, E., 1998. Population and community responses of phytoplankton to fluctuating light. Oecologia 117, 247-257. 
Litchman, E., Klausmeier, C.A., Schofield, O.M., Falkowski, P.G., 2007. The role of functional traits and trade-offs in structuring phytoplankton communities: Scaling from cellular to ecosystem level. Ecology Letters 10, 1170-1181. doi:10.1111/j.1461-0248.2007.01117.x.

Long, M.C., Lindsay, K., Holland, M.M., 2015. Modeling photosynthesis in sea ice-covered waters. Journal of Advances in Modeling Earth Systems 7, 1189-1206.

Long, M.C., Moore, J.K., Lindsay, K., Levy, M.N., Doney, S.C., Luo, J.Y., Krumhardt, K.M., Letscher, R.T., Grover, M., Sylvester, Z.T., 2021. Simulations with the marine biogeochemistry library (marbl) .

Longhurst, A.R., Harrison, W.G., 1988. Vertical nitrogen flux from the oceanic photic zone by diel migrant zooplankton and nekton. Deep Sea Research Part A. Oceanographic Research Papers 35, 881-889.

López-Sandoval, D.C., Rodríguez-Ramos, T., Cermeño, P., Sobrino, C., Marañón, E., 2014. Photosynthesis and respiration in marine phytoplankton: relationship with cell size, taxonomic affiliation, and growth phase. Journal of experimental marine biology and ecology 457, 151-159.

Luo, J.Y., Condon, R.H., Stock, C.A., Duarte, C.M., Lucas, C.H., Pitt, K.A., Cowen, R.K., 2020. Gelatinous zooplankton-mediated carbon flows in the global oceans: a data-driven modeling study. Global Biogeochemical Cycles 34, e2020GB006704.

Luo, Y.W., Lima, I.D., Karl, D.M., Deutsch, C., Doney, S., 2014. Data-based assessment of environmental controls on global marine nitrogen fixation. Biogeosciences 11, 691-708.

Ángel López-Urrutia, Martin, E.S., Harris, R.P., Irigoien, X., 2006. Scaling the metabolic balance of the oceans. Proceedings of the National Academy of Sciences 103, 8739-8744.

\footnotetext{
MacIntyre, S., $1998 . \quad$ Turbulent mixing and resource supply to phytoplankton. URL: https://agupubs .onlinelibrary.wiley.com/doi/abs/10.1029/CE054p0561, doi:https://doi.org/10.1029/CE054p0561.
} 
Marañón, E., Cermeño, P., López-Sandoval, D.C., Rodríguez-Ramos, T., Sobrino, C., Huete-Ortega, M., Blanco, J.M., Rodríguez, J., 2013. Unimodal size scaling of phytoplankton growth and the size dependence of nutrient uptake and use. Ecology Letters 16, 371-379. doi:10.1111/ele.12052.

Margalef, R., 1978. Life-forms of phytoplankton as survival alternatives in an unstable environment. Oceanologica acta 1, 493-509.

Marquet, P.A., Quiñones, R.A., Abades, S., Labra, F., Tognelli, M., Arim, M., Rivadeneira, M., 2005. Scaling and power-laws in ecological systems. Journal of Experimental Biology 208, 1749-1769.

Mayorga, E., Seitzinger, S.P., Harrison, J.A., Dumont, E., Beusen, A.H., Bouwman, A., Fekete, B.M., Kroeze, C., Van Drecht, G., 2010. Global nutrient export from watersheds 2 (news 2): model development and implementation. Environmental Modelling \& Software 25, 837-853.

McCarthy, J.J., Carpenter, E.J., 1979. Oscillatoria (trichodesmium) thiebautii (cyanophyta) in the central north atlantic ocean 12 . Journal of Phycology $15,75-82$.

Menden-Deuer, S., Lessard, E.J., 2000. Carbon to volume relationships for dinoflagellates, diatoms, and other protist plankton. Limnol. Oceanogr 45, $569-579$.

Moeller, H.V., Laufkötter, C., Sweeney, E.M., Johnson, M.D., 2019. Lightdependent grazing can drive formation and deepening of deep chlorophyll maxima. Nature communications 10, 1-8.

Monteiro, F.M., Dutkiewicz, S., Follows, M.J., 2011. Biogeographical controls on the marine nitrogen fixers. Global Biogeochemical Cycles 25.

Moore, C.M., Mills, M.M., Arrigo, K.R., Berman-Frank, I., Bopp, L., Boyd, P.W., Galbraith, E.D., Geider, R.J., Guieu, C., Jaccard, S.L., Jickells, T.D., Roche, J.L., Lenton, T.M., Mahowald, N.M., Marañón, E., Marinov, I., Moore, J.K., Nakatsuka, T., Oschlies, A., Saito, M.A., Thingstad, T.F., Tsuda, A., Ulloa, O., 2013a. Processes and patterns of oceanic nutrient limitation. Nature Geoscience 6, 701-710. doi:10.1038/ngeo1765. 
Moore, J.K., Doney, S.C., Kleypas, J.A., Glover, D.M., Fung, I.Y., 2001. An intermediate complexity marine ecosystem model for the global domain. Deep Sea Research Part II: Topical Studies in Oceanography 49, 403-462.

Moore, J.K., Doney, S.C., Lindsay, K., 2004a. Upper ocean ecosystem dynamics and iron cycling in a global three-dimensional model. Global Biogeochemical Cycles 18 .

Moore, J.K., Doney, S.C., Lindsay, K., 2004b. Upper ocean ecosystem dynamics and iron cycling in a global three-dimensional model. Global Biogeochemical Cycles 18 .

Moore, J.K., Lindsay, K., Doney, S.C., Long, M.C., Misumi, K., 2013b. Marine ecosystem dynamics and biogeochemical cycling in the community earth system model [cesm1 (bgc)]: Comparison of the 1990s with the 2090s under the rcp4. 5 and rcp8. 5 scenarios. Journal of Climate 26, 9291-9312.

Moore, L.R., Chisholm, S.W., 1999. Photophysiology of the marine cyanobacterium prochlorococcus: ecotypic differences among cultured isolates. Limnology and Oceanography 44, 628-638.

Moore, L.R., Post, A.F., Rocap, G., Chisholm, S.W., 2002. Utilization of different nitrogen sources by the marine cyanobacteria prochlorococcus and synechococcus. Limnology and oceanography 47, 989-996.

Moriarty, R., O'Brien, T.D., 2013. Distribution of mesozooplankton biomass in the global ocean. Earth System Science Data 5, 45-55. doi:10.5194/essd5-45-2013.

Najjar, R., Orr, J., Sabine, C., Joos, F., 1999. Biotic-howto. Internal OCMIP Report, LSCE/CEA Saclay, Gif-sur-Yvette, France 15.

Nelson, D.M., Tréguer, P., Brzezinski, M.A., Leynaert, A., Quéguiner, B., 1995. Production and dissolution of biogenic silica in the ocean: revised global estimates, comparison with regional data and relationship to biogenic sedimentation. Global Biogeochemical Cycles 9, 359-372.

O'Brien, T.D., 2005. Copepod, a global plankton database: a review of the 2005 database contents and creation of new global zooplankton biomass fields . 
O’Neill, R., DeAngelis, D., Pastor, J., Jackson, B., Post, W., 1989. Multiple nutrient limitations in ecological models. Ecological Modelling 46, 147-163.

Oostende, N.V., Dussin, R., Stock, C.A., Barton, A.D., Curchitser, E., Dunne, J.P., Ward, B.B., 2018. Simulating the ocean's chlorophyll dynamic range from coastal upwelling to oligotrophy. Progress in Oceanography 168, 232-247. doi:10.1016/j.pocean.2018.10.009.

Park, J.Y., Stock, C.A., Dunne, J.P., Yang, X., Rosati, A., 2019. Seasonal to multiannual marine ecosystem prediction with a global earth system model. Science 365, 284-288.

Peters, R.H., Wassenberg, K., 1983. The effect of body size on animal abundance. Oecologia 60, 89-96.

Pitt, K.A., Duarte, C.M., Lucas, C.H., Sutherland, K.R., Condon, R.H., Mianzan, H., Purcell, J.E., Robinson, K.L., Uye, S.I., 2013. Jellyfish body plans provide allometric advantages beyond low carbon content. PLoS ONE 8. doi:10.1371/journal.pone.0072683.

Reynolds, C., 2006. The Ecology of Phytoplankton. Ecology, Biodiversity and Conservation, Cambridge University Press. URL: https://books .google.com/books?id=gDz5jGsPWZYC.

Richardson, K., Beardall, J., Raven, J.A., 1983. Adaptation of unicellular algae to irradiance: an analysis of strategies. New Phytologist 93, 157-191.

Ryther, J.H., 1969. Photosynthesis and fish production in the sea. New Series 166, 72-76.

Sarmiento, J.L., Slater, R., Barber, R., Bopp, L., Doney, S.C., Hirst, A.C., Kleypas, J., Matear, R., Mikolajewicz, U., Monfray, P., Soldatov, V., Spall, S.A., Stouffer, R., 2004. Response of ocean ecosystems to climate warming. Global Biogeochemical Cycles 18. doi:10.1029/2003GB002134.

Sathyendranath, S., Stuart, V., Nair, A., Oka, K., Nakane, T., Bouman, H., Forget, M.H., Maass, H., Platt, T., 2009. Carbon-to-chlorophyll ratio and growth rate of phytoplankton in the sea. Marine Ecology Progress Series 383, 73-84. doi:10.3354/meps07998. 
Schiebel, R., 2002. Planktic foraminiferal sedimentation and the marine calcite budget. Global Biogeochemical Cycles 16, 3-1.

Sheldon, R., Sutcliffe Jr, W., Paranjape, M., 1977. Structure of pelagic food chain and relationship between plankton and fish production. Journal of the Fisheries Board of Canada 34, 2344-2353.

Six, K.D., Maier-Reimer, E., 1996. Effects of plankton dynamics on seasonal carbon fluxes in an ocean general circulation model. Global Biogeochemical Cycles 10, 559-583.

Smith, R., Jones, P., Briegleb, B., Bryan, F., Danabasoglu, G., Dennis, J., Dukowicz, J., Eden, C., Fox-Kemper, B., Gent, P., 2010. The parallel ocean program (pop) reference manual ocean component of the community climate system model (ccsm) and community earth system model (cesm). LAUR-01853 141, 1-140.

Spitz, Y., Moisan, J., Abbott, M., 2001. Configuring an ecosystem model using data from the bermuda atlantic time series (bats). Deep Sea Research Part II: Topical Studies in Oceanography 48, 1733-1768.

Stawiarski, B., Buitenhuis, E.T., Quéré, C.L., 2016. The physiological response of picophytoplankton to temperature and its model representation. Frontiers in Marine Science 3. doi:10.3389/fmars.2016.00164.

Steele, J.H., Henderson, E.W., 1992. The role of predation in plankton models. Journal of Plankton Research 14, 157-172.

Stefels, J., Dijkhuizen, L., Gieskes, W., 1995. Dmsp-lyase activity in a spring phytoplankton bloom off the dutch coast, related to phaeocystis sp. abundance. Marine Ecology Progress Series 123, 235-243.

Steinberg, D.K., Carlson, C.A., Bates, N.R., Goldthwait, S.A., Madin, L.P., Michaels, A.F., 2000. Zooplankton vertical migration and the active transport of dissolved organic and inorganic carbon in the sargasso sea. Deep Sea Research Part I: Oceanographic Research Papers 47, 137-158.

Steinberg, D.K., Carlson, C.A., Bates, N.R., Johnson, R.J., Michaels, A.F., Knap, A.H., 2001. Overview of the us jgofs bermuda atlantic time-series study (bats): a decade-scale look at ocean biology and biogeochemistry. 
Deep Sea Research Part II: Topical Studies in Oceanography 48, 14051447.

Steinberg, D.K., Landry, M.R., 2017. Zooplankton and the ocean carbon cycle. Annual review of marine science 9, 413-444.

Stemmann, L., Boss, E., 2012. Plankton and particle size and packaging: from determining optical properties to driving the biological pump. Annual Review of Marine Science 4, 263-290.

Stock, C., Dunne, J., 2010. Controls on the ratio of mesozooplankton production to primary production in marine ecosystems. DeepSea Research Part I: Oceanographic Research Papers 57, 95-112. doi:10.1016/j.dsr.2009.10.006.

Stock, C., Dunne, J., John, J., 2014a. Drivers of trophic amplification of ocean productivity trends in a changing climate. Biogeosciences 11, 71257135 .

Stock, C.A., Dunne, J.P., Fan, S., Ginoux, P., John, J., Krasting, J.P., Laufkötter, C., Paulot, F., Zadeh, N., 2020. Ocean biogeochemistry in gfdl's earth system model 4.1 and its response to increasing atmospheric co2. Journal of Advances in Modeling Earth Systems 12. doi:10.1029/2019MS002043.

Stock, C.A., Dunne, J.P., John, J.G., 2014b. Global-scale carbon and energy flows through the marine planktonic food web: An analysis with a coupled physical-biological model. Progress in Oceanography 120, 1-28. doi:10.1016/j.pocean.2013.07.001.

Straile, D., 1997. Gross growth efficiencies of protozoan and metazoan zooplankton and their dependence on food concentration, predator-prey weight ratio, and taxonomic group. Limnology and Oceanography 42, $1375-1385$.

Tang, E.P.Y., 1995. The allometry of algal growth and respiration .

Tang, W., Wang, S., Fonseca-Batista, D., Dehairs, F., Gifford, S., Gonzalez, A.G., Gallinari, M., Planquette, H., Sarthou, G., Cassar, N., 
2019. Revisiting the distribution of oceanic n2 fixation and estimating diazotrophic contribution to marine production. Nature Communications 10, 831. URL: https://doi .org/10.1038/s41467-019-08640-0, doi:10.1038/s41467-019-08640-0.

Taniguchi, D.A., Franks, P.J., Poulin, F.J., 2014. Planktonic biomass size spectra: An emergent property of size-dependent physiological rates, food web dynamics, and nutrient regimes. Marine Ecology Progress Series 514, 13-33. doi:10.3354/meps10968.

Tréguer, P., Bowler, C., Moriceau, B., Dutkiewicz, S., Gehlen, M., Aumont, O., Bittner, L., Dugdale, R., Finkel, Z., Iudicone, D., Jahn, O., Guidi, L., Lasbleiz, M., Leblanc, K., Levy, M., Pondaven, P., 2018. Influence of diatom diversity on the ocean biological carbon pump. Nature Geoscience 11, 27-37. doi:10.1038/s41561-017-0028-x.

Vallina, S.M., Follows, M., Dutkiewicz, S., Montoya, J.M., Cermeno, P., Loreau, M., 2014. Global relationship between phytoplankton diversity and productivity in the ocean. Nature communications 5, 1-10.

Wang, W.L., Moore, J.K., Martiny, A.C., Primeau, F.W., 2019. Convergent estimates of marine nitrogen fixation. Nature 566, 205-211.

Ward, B.A., Dutkiewicz, S., Follows, M.J., 2014. Modelling spatial and temporal patterns in size-structured marine plankton communities: topdown and bottom-up controls. Journal of Plankton Research 36, 31-47.

Ward, B.A., Dutkiewicz, S., Jahn, O., Follows, M.J., 2012. A size-structured food-web model for the global ocean. Limnology and Oceanography 57, 1877-1891. doi:10.4319/lo.2012.57.6.1877.

Ward, B.A., Follows, M.J., 2016. Marine mixotrophy increases trophic transfer efficiency, mean organism size, and vertical carbon flux. Proceedings of the National Academy of Sciences 113, 2958-2963.

Wu, J., Sunda, W., Boyle, E.A., Karl, D.M., 2000. Phosphate depletion in the western north atlantic ocean. Science 289, 759-762.

Yool, A., Popova, E., Anderson, T., 2013. Medusa-2.0: an intermediate complexity biogeochemical model of the marine carbon cycle for climate 

available under aCC-BY-NC-ND 4.0 International license.

1784 change and ocean acidification studies. Geoscientific Model Development $1785 \quad 6,1767-1811$.

${ }_{1786}$ Yuan, L.L., Pollard, A.I., 2018. Changes in the relationship between zoo1787 plankton and phytoplankton biomasses across a eutrophication gradient. $1788 \quad$ Limnology and oceanography 63, 2493-2507. 